\title{
Effects of Farmland Heterogeneity \\ on Bat Species Richness and Activity \\ in Agricultural Eastern Ontario
}

by

Liv Monck-Whipp

A thesis submitted to the Faculty of Graduate and Postdoctoral

Affairs in partial fulfillment of the requirements for the degree of

Master of Science

in

Biology

Carleton University

Ottawa, Ontario

(C) 2015, Liv Monck-Whipp 


\begin{abstract}
The effects of semi-natural habitat amount in agricultural landscapes on bat species richness and activity levels are well documented, however the way crops are arranged (configurational heterogeneity) or their diversity (compositional heterogeneity) may also influence bat communities. Smaller field sizes should increase both the accessibility and quality of foraging habitat. Increased diversity of crop types may benefit bats by creating more diverse, abundant, and temporally stable communities of prey insects. We conducted acoustic surveys in agricultural landscapes in Eastern Ontario to test predictions that bat species richness and activity should increase with increasing compositional and configurational heterogeneity of crops. Field size appeared to have mixed effects on bat activity levels across species while total bat activity and activity of several species (Lasiurus noctivagans, L. cinereus, Myotis septentrionalis, and Eptesicus fuscus) was higher in landscapes with higher diversity of crops. We hypothesize this is because diverse crops create more temporally stable prey communities.
\end{abstract}




\section{Acknowledgements}

Firstly, I would like to thank my supervisor, Lenore Fahrig, for her guidance and support throughout the research and writing process. I have learned so much from your practical, elegant approaches to understanding ecology, and I greatly appreciate all of the time and insights you have given me.

Thanks also to my committee members Charles Francis, and Antoine Morin for their feedback at committee meetings, and for their comments on more than a couple drafts. I would also like to thank Adam Smith for all of his enthusiasm and advice when coaching me through statistical storms.

Thanks to Kevin Ethier for orienting me into the world of bat ecology, for his advice regarding fieldwork, and for making this project possible.

Thanks to the entire amazing group of people who worked on the "Ag Project", especially to Jude Girard for somehow managing to oversee several field crews while finishing up her own doctorate. Your organization skills are legend, and your guidance invaluable. Special thanks as well to Tess Walsh for all of her assistance in the field and for her excellent music collection for long car rides (even if she might have been just trying to get me to stop rambling).

Thanks to all members of the GLEL Lab for their support, and especially to Susie Crow, Dan Bert, Sara Collins, Tom Hotte, Alex Koumaris, Sandra Martins De Freita, and Gen Perkins for providing feedback on early drafts, orientation to the GLEL, and so much encouragement. Thanks also to my friends Jess Morrison, Julia Riley, and James Baxter-Gilbert for being inspiring ecologists and educators, and for always reminding me 
how incredible studying nature can be. Thank you to my partner Cameron Bennett for listening to me babble about bats in the middle of the night.

Finally, I would like to thank all the farmers and landowners who graciously allowed us to conduct research on their property. They put food on all our tables, and are some of the most interested, active, and important stewards of the land out there. 


\section{Table of Contents}

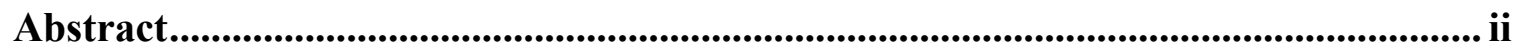

Acknowledgements ............................................................................................................................. iii

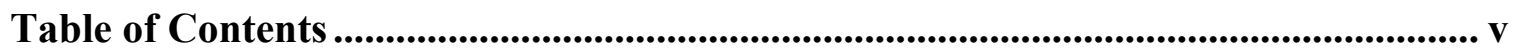

List of Tables ............................................................................................................................... vii

List of Figures.............................................................................................................................. viii

List of Appendices.......................................................................................................................... $\mathrm{x}$

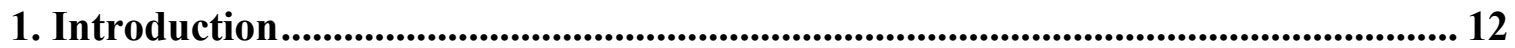

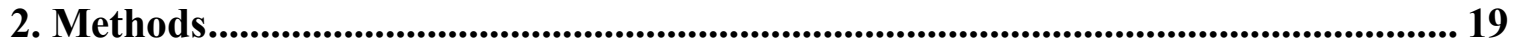

2.1 Study Region and Landscape Selection......................................................... 19

2.2 Landscape Predictor Variables ..................................................................... 19

2.3 Bat Response Variables...............................................................................2

2.3.1 Acoustic Surveys..............................................................................20

2.3.2 Bat Call Classification..........................................................................22

2.4 Insect Trapping and Weather Monitoring …………………………………....24

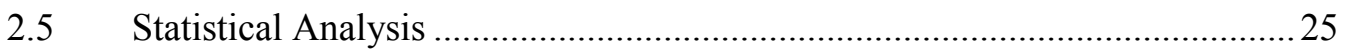

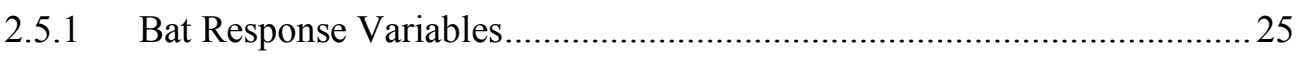

2.5.2 Selection of Confounding Variables for Inclusion in Landscape Models..26

2.5.3 Modelling Landscape Effects.................................................................2 26

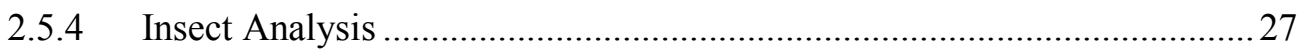

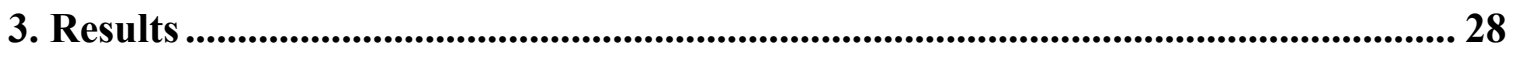

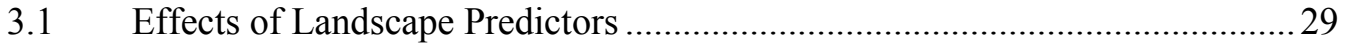

3.2 Selection of Confounding Variables for Inclusion in Landscape Models........30

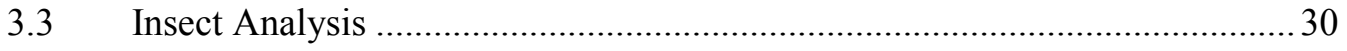




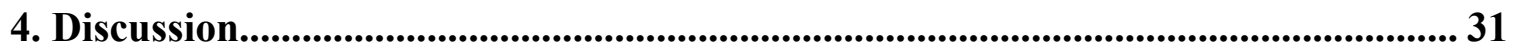

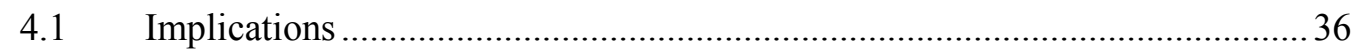

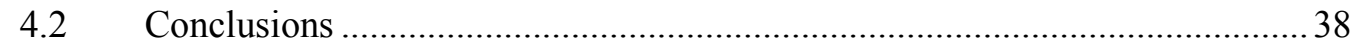

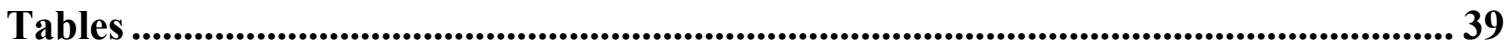

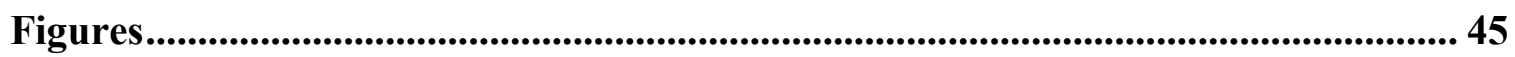

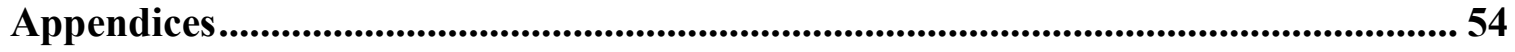

References .......................................................................................................................... 71 


\section{List of Tables}

Table 1: Pearson correlations between potential confounding variables on bat species richness, total activity, and activity levels of individual species and landscape variables at $3 \mathrm{~km}$ scale in agricultural study landscapes in Eastern Ontario 39

Table 2: Top models of all combinations of potential confounding variables of bat responses ranked by AICc. Null models included only landscape identity as a random effect term to account for repeated measures on landscapes.

Table 3: Pearson correlations of bat responses and abundances of different size and taxonomic categories of insects trapped during acoustic surveys for bats in agricultural landscapes in Eastern Ontario

Table 4: Pearson correlations between landscape predictor variables in agricultural Eastern Ontario study landscapes and the abundance of insects from size and taxonomic categories of insects most highly correlated with bat species richness and activity responses during acoustic surveys.

Table 5: Coefficients of variation of insect totals for total insects, as well as size and taxonomic categories of insects most highly correlated with bat species richness and activity responses during acoustic surveys 


\section{List of Figures}

Figure 1: Increasing configurational heterogeneity independent of compositional heterogeneity - each shade of grey represents a different crop type. The landscape on the right has higher configurational heterogeneity, but both landscapes have the same amount of each crop type (same compositional heterogeneity)..................................................... 45

Figure 2: Increasing compositional heterogeneity independent of configurational heterogeneity - each shade of grey represents a different crop type. The landscape on the right has higher compositional heterogeneity, but both have the same 4 field layout (same configurational heterogeneity). 45

Figure 3: Location of study landscapes within agricultural Eastern Ontario. Mean field size (LogMFS) and Shannon Diversity of agriculture (SHDI) existed on a continuous scale but were categorized as "High" or "Low" to allow rotation of sampling effort to avoid correlation of these categories with date. Landscapes here are represented at the $1 \mathrm{~km} \times 1 \mathrm{~km}$ scale 46

Figure 4: Example of agricultural study landscape with different land uses mapped at 3 spatial extents (inner square $=1 \mathrm{~km} \times 1 \mathrm{~km}$, middle square $=2 \mathrm{~km} \times 2 \mathrm{~km}$, outer square $=3 \mathrm{~km} \times 3 \mathrm{~km})$

Figure 5: Diagram of layout of sampling equipment at each acoustic survey point, including bat recording station, and weather station/insect trap set up along field boundaries.

Figure 6: Standardized coefficients of Log Mean Field Size at $3 \mathrm{~km}$ in generalized mixed models of bat responses to landscape predictor variables (error bars show 95\% confidence intervals, $*$ indicates a $p$-value of $<0.05, \dagger$ indicates $p$-value of $<0.10$ ) 
Figure 7: Standardized coefficients of Shannon Diversity of agriculture at $3 \mathrm{~km}$ in generalized mixed models of bat responses to landscape predictor variables (error bars show $95 \%$ confidence intervals, $*$ indicates a $p$-value of $<0.05, \dagger$ indicates $p$-value of $<0.10)$ 50

Figure 8: Standardized coefficients of Proportion of Agricultural Cover at $3 \mathrm{~km}$ in generalized mixed models of bat responses to landscape predictor variables (error bars show $95 \%$ confidence intervals, $*$ indicates a $p$-value of $<0.05, \dagger$ indicates $p$-value of $<0.10)$

Figure 9: Examples of agricultural cover in typical landscape in the lowest quartile of Shannon Diversity of agriculture (left) and the highest quartile of Shannon Diversity of Agriculture (right), and means of bat responses observed in landscapes within these quartiles

Figure 10: Example of theoretical agricultural landscape which promotes bat activity. Agricultural land use is indicated by grey or cross hatching, while natural and semi-natural land use is indicated in green. Different shades of grey represent different crop types, with horizontal hatching representing hay, while diagonal hatching represents pasture. Forest fragments are indicated by rounded green areas, and at least one is adjacent to each field. Individual scattered trees are indicated by green triangles. Field margins have semi-natural vegetation such as grass, shrubs, and brush. 53 


\section{List of Appendices}

Appendix A Standardized coefficients of landscape variables at 1,2, and 3km scales in GLMM models of bat responses.

A.1 Standardized coefficients of Log Mean Field Size at 1, 2, and $3 \mathrm{~km}$ scales in generalized mixed models of bat responses to landscape predictor variables (error bars show 95\% confidence intervals, $*$ indicates a $\mathrm{p}$-value of $<0.05, \dagger$ indicates $\mathrm{p}$-value of $<0.10) \ldots \ldots \ldots .55$ A.2 Standardized coefficients Shannon Diversity of agriculture at 1, 2, and $3 \mathrm{~km}$ scales in generalized mixed models of bat responses to landscape predictor variables (error bars show $95 \%$ confidence intervals, $*$ indicates a p-value of $<0.05, \dagger$ indicates $p$-value of $<0.10) \ldots 56$ A.3 Standardized coefficients of Proportion of Agricultural Cover at 1, 2, and $3 \mathrm{~km}$ scales in generalized mixed models of bat responses to landscape predictor variables (error bars show $95 \%$ confidence intervals, $*$ indicates a p-value of $<0.05, \dagger$ indicates $p$-value of $<0.10$ )

Appendix B Correlations between bat responses and landscape variables. .58

B.1 Correlations between Bat Responses and Log of Mean Field Size at $3 \mathrm{~km}$ in study landscapes in Eastern Ontario

B.2 Correlations between Bat Responses and Shannon Diversity of Agriculture at $3 \mathrm{~km}$ in study landscapes in Eastern Ontario

Appendix C Pearson correlations between percentage forest cover at $3 \mathrm{~km}$ scale and bat response variables recorded in acoustic surveys in agricultural Eastern Ontario study landscapes

Appendix D Raw Data - Bat Responses: Species richness, total number of calls, and calls per species recorded at each surveying point on a given night.

Appendix E Raw Data - Insect totals and potential confounding variables at surveying points on a given night. .66 
Appendix F Raw Data - Study landscapes: Location, Log of mean field size, proportion agricultural cover, Shannon Diversity of agriculture, and proportion forest cover............69 


\section{Introduction}

Agriculture constitutes approximately $40 \%$ of land cover worldwide (Foley et al. 2005) and hence represents significant potential habitat for species that are able to survive in and use agricultural areas or the semi-natural habitats associated with them (Benton et al. 2003, Tscharntke et al. 2005). These areas can support native plants (e.g. Boutin et al. 2008), insects (e.g. Wickramasinghe and Harris 2004, Marini et al. 2009) and other invertebrates (e.g. Sunderland and Samu 2000, Boschi and Baur 2007, Leslie et al. 2012), mammals (e.g. Michel et al. 2006, Pocock and Jetnnings 2008, Boughey et al. 2011), birds (e.g. Chamberlain et al. 2000, Harvey et al. 2006, Garfinkel and Johnson 2015), fish (e.g. Colvin et al. 2009, Chester and Robson 2013), reptiles (e.g. Klug et al. 2010, Rotem et al. 2013) and amphibians (e.g. Attademo et al. 2005, Chester and Robson 2013). Some native species may use only semi-natural habitat within agricultural areas, while others may use crops or a mixture of crops and semi-natural area as habitat.

Farming practices within agricultural areas may influence a landscape's ability to support higher abundances or diversity of different taxa (Björklund et al. 1999, Wickramasinghe et al. 2003, Fuller et al. 2005, Fahrig et al. 2015). Within Canada, approximately $30.2 \%$ (19.6 million hectares) of total farm area is recognized as seminatural habitat (i.e. woodlands, wetlands, and natural pastures), and a further 54.5\% (35.4 million hectares) of total farm area is cropland (i.e. field crops, hay, vegetables, sod, fruit, berries and nuts) (Jeswiet et al. 2015). As demands on food production increase, conversion of non-cropped areas to crops, and intensive farming practices such as simplified crop rotation, and use of pesticides, fertilizers and herbicides, are likely to increase (Benton et al. 2003). The wide extent of farmland means that any change in its 
ability to support native wildlife could produce substantial effects on biodiversity (Fahrig et al. 2011)

Increasing the amount of semi-natural cover within agricultural systems can be beneficial to native biodiversity. Semi-natural habitat within agriculture can include small forest patches, native grasslands used for pasture, ponds and other aquatic habitats, and wooded vegetation along streams, roads, or field boundaries (Bennett et al. 2006). These types of habitat can support diverse and stable ecological communities (Devictor and Jiguet 2007), can act as sources for sink populations in the surrounding landscape (Holland and Fahrig 2000, Sunderland and Samu 2000), and can provide crucial resources for species requiring multiple habitat types (Fahrig et al. 2011). Higher amounts of semi-natural habitat within agricultural areas are associated with increased diversity across a range of taxa including; birds (Trzcinski et al. 1999, Billeter et al. 2008), small mammals (Nupp and Swihart 2000), bats (Duchamp et al. 2004, Gorresen and Willig 2004, Ethier and Fahrig 2011), amphibians (Vallan 2000), and arthropods (Aviron et al. 2005, Billeter et al. 2008).

However, ways of enhancing agricultural biodiversity without reducing the area of production are important conservation tools to discover. The influence of the structure of cropped vegetation on biodiversity within agricultural landscapes has not been studied extensively, or for many taxa (Fahrig et al. 2011), although it may have a large role to play in the ecology of many species which use agricultural landscapes (Benton et al. 2003). In areas where demand for agriculture is high, or farming practices are becoming more intensive it is crucial to know how to conserve native biodiversity when natural habitat is converted to farmland. It can be difficult to get farmers to adopt policies which 
remove productive crops in favour of creating semi-natural habitat that does not directly increase agricultural productivity (Burton et al. 2008). In light of this, investigating ways of increasing the carrying capacity of native wildlife in crop-producing areas is important for creating agricultural guidelines, and can complement policies aimed at preserving semi-natural habitat within agricultural areas.

One potential way to enhance biodiversity without taking land out of production is to alter the structure of crop cover within agricultural landscapes, while maintaining the same amount of crop cover. Species richness tends to respond to agricultural changes at a landscape, not local, scale (Hendrickx et al. 2007), and ecological services occur at a landscape scale (Tscharntke et al. 2005), so investigating ways of enhancing agricultural biodiversity without reducing the area of production at this scale is important for guiding management policy. The structure of a landscape is determined by the land cover types it contains, and their spatial configuration and composition. Configuration refers to how cover types within a landscape are arranged, while composition refers to the relative makeup of those cover types. For native species, different crops can represent different resources, corridors or barriers for movement, so their configuration and/or composition may affect species presence or abundance within an agricultural landscape (Fahrig et al. 2011).

Landscapes can be more or less heterogenous in their configuration or composition. Figure 1 and 2 illustrate how configurational heterogeneity can vary independently of compositional heterogeneity, and vice versa. More interspersion of cover types, and higher edge density increase the configurational heterogeneity of a landscape (Lovett et al. 2004). Configurational heterogeneity may affect proximity of 
different resources to each other (e.g. tall crops that can be used as cover from predators next to shorter crops that provide foraging opportunities) and/or the ability of an organism to move between semi-natural habitat fragments (e.g. wide square shaped fields may be riskier to cross while strip farming can provide shorter corridors between fields). A higher number of cover types, or more evenness of cover type proportions increases a landscape's compositional heterogeneity. Compositional heterogeneity may affect the variety of resources available and may contribute to habitat complementation (Dunning et al. 1992) for some species (Benton et al. 2003) (e.g. hay fields provide breeding grounds, row crops provide seeds for granivorous birds).

Configurational and compositional heterogeneity can be highly correlated, especially within agricultural systems, for example landscapes with smaller fields tend to have a greater number of types of crops. The relative roles of these two landscape metrics in determining biodiversity in agricultural ecosystems are not well explored (Fahrig et al. 2011). An additional challenge in studying the effects of heterogeneity of crop cover is that agricultural landscapes with more heterogenous cropped area also tend to have a larger proportion of semi-natural habitat, which may account for any positive effects of crop heterogeneity. It is necessary to disentangle the effects on biodiversity of agricultural configurational and compositional heterogeneity from each other, and from the well documented positive effects of semi-natural habitat amount to understand how to structure farmland to promote biodiversity.

Bat populations are particularly important to agriculture in North America as they contribute potentially massive amounts of pest insect removal in farmlands (Boyles et al. 2011). The feeding niche of nocturnal aerial insectivores is only occupied by bats, small 
owls, and caprimulgiform birds (Humphrey 1975) and so bats are a critical link in the agricultural wildlife food web. Bats are likely responsible for suppressing pest populations (Kunz et al. 2011, Boyles et al. 2013), as a single colony can remove millions of pests annually (e.g. cucumber beetles, stinkbugs, leafhoppers, and corn earworm moths) (Whitaker 1995). Eastern Ontario is home to 8 species of bats, (Myotis lucifugus, M. septentrionalis, M. leibii, Lasiurus borealis, L. cinereus, Eptesicus fuscus, Perimyotis subflavus, and Lasionycteris noctivagans), all of which are nocturnal insectivores, and with the exception of M. leibii, all are commonly found in agricultural landscapes (van Zyll de Jong 1985). While some species may prefer certain types of prey, all are known to feed opportunistically on many insect taxa (van Zyll de Jong 1985, Agosta et al. 2003, Clare et al. 2009, 2011). As bats provide an ecological service to farmers, and represent a unique group of threatened mammals within Canada (Boyles et al. 2011), understanding how agricultural landscape structure influences bat diversity and abundance could be useful for integrative land management practices.

Previous studies have focused on the relationship between bat diversity and abundance and forest amount and fragmentation in agricultural landscapes. In general, agricultural landscapes with more forest appear to have higher bat diversity and abundance (Gehrt and Chelsvig 2004, Duchamp and Swihart 2008). Landscapes with moderate amounts of forest may have higher, or comparable species richness to contiguously forested landscapes as these areas support generalists as well as species which prefer forest and open areas (Gorresen and Willig 2004). There is also growing evidence that increased interspersion of forest and crops within agricultural landscapes may benefit bat communities (Estrada and Coates-Estrada 2002, Gorresen and Willig 
2004, Bernard and Fenton 2007, Ethier and Fahrig 2011). This may be due to habitat complementation (Dunning et al. 1992) between roosting habitat (forest) and foraging habitat (agricultural fields) (Ethier and Fahrig 2011).

The way crops are arranged (configurational heterogeneity) or their diversity (compositional heterogeneity) may also affect bats' ability to use agricultural landscapes. A larger number of crop-crop interfaces created by smaller field sizes, or more complex field shapes should increase both the accessibility and quality of foraging habitat, resulting in higher bat activity levels. Bats prefer to forage and commute along linear landscape elements (Limpens et al. 1989, Verboom and Huitema 1997, Boughey et al. 2011, Lentini et al. 2012, Frey-Ehrenbold et al. 2013), which may function as navigational references, sources of insect prey, shelter from wind and/or protection from predators (Verboom and Huitema 1997). We predict that decreasing the mean field size would increase the diversity and abundance of bat species in an agricultural landscape.

The diversity of crop types in a landscape may also impact bat communities by supporting more diverse and abundant communities of prey insects. Some insect species use one or more crops as part of their life cycle (e.g. for food, breeding areas, or as cover) and a greater variety of crops will likely support a greater variety of these insects within an agricultural landscape. Agricultural landscapes with more diverse crops may also provide a more temporally stable foraging habitat for generalist bat species as different insects are active at different times of night (Rydell et al. 2013), and population cycles of pests may stagger food availability seasonally. We predicted that increasing the ShannonWiener diversity index of agricultural cover would increase the diversity and abundance of bats in an agricultural landscape. 
We tested the above predictions that bat species richness and activity should increase with increasing configurational and compositional heterogeneity of crops in agricultural eastern Ontario, using $3 \mathrm{~km} \times 3 \mathrm{~km}$ agricultural landscapes. We chose mean field size of crops as an index of configurational heterogeneity, and Shannon-diversity of crops as an index of compositional heterogeneity and used a landscape selection procedure which minimized correlation between these two variables. We then conducted acoustic surveys for bat species richness and activity (as a proxy for abundance). We also trapped insects overnight to investigate if landscape heterogeneity effects on bats were related to landscape heterogeneity effects on their insect prey. Finally, we combined our results with previous research on forest structure and bat diversity and abundance to draw inferences about the kinds of agricultural landscapes that favour diverse, active bat assemblages. 


\section{Methods}

\subsection{Study Region and Landscape Selection}

This study was conducted in rural Eastern Ontario, near Ottawa, Canada (Figure 3). Approximately $50 \%$ of the $15500 \mathrm{~km}^{2}$ study area is covered by crop or pasture (Statistics Canada 2006) interspersed with fragments of mixed and deciduous forest (Thompson 2000).

Pasher et al. (2013) performed landscape selection as part of a larger project (Fahrig et al. 2015), using a moving window analysis on satellite imagery (Landsat-5 images, $30 \mathrm{~m}$ x $30 \mathrm{~m}$ pixel, from the 2007 growing season) to select a set of sample landscapes that met the following criteria. Each potential landscape was $3 \mathrm{~km} \times 3 \mathrm{~km}$ in size, with 40-90\% agricultural cover. From these a set of landscapes was selected such that there was a minimum of $3.5 \mathrm{~km}$ between landscape centres; no spatial autocorrelation between landscapes and their mean field size or Shannon Diversity of agriculture; and minimal correlation between mean field size and the Shannon Diversity of agriculture (Pasher et al. 2013).

We conducted acoustic surveys for bats at a random selection of 46 of the 93 landscapes selected for the larger project (Fahrig et al. 2015).

\subsection{Landscape Predictor Variables}

In 2012 aerial photography of all the landscapes was commissioned to obtain accurate measurements of the landscape variables during the field season in which bats 
were surveyed. Pasher et al. (2013) used these photos to create detailed land cover maps of each landscape at $40 \mathrm{~cm}$ resolution, at 3 spatial extents $-1 \times 1 \mathrm{~km}, 2 \times 2 \mathrm{~km}$, and $3 \times 3 \mathrm{~km}$ (e.g. Figure 4). Field crews validated the maps by visiting each landscape. Separate crop or pasture fields were delineated based on visible field boundaries, a change in crop type, or both. Therefore, areas of the same crop type that were separated by a non-crop field boundary were considered separate fields, and areas of different crop types that were not separated by a non-crop boundary were also considered separate fields. From these detailed land cover maps, we calculated for each landscape, at each spatial extent (1, 2, and $3 \mathrm{~km}$ ), three landscape variables: mean size of all agricultural fields in the landscape (configurational heterogeneity), Shannon Diversity of agricultural types within the farmland portion of the landscape (compositional heterogeneity) and proportion of the landscape covered by crops or pasture (proportion agriculture) (Pasher et al. 2013). We included proportion of agriculture to control for potential effects of overall agricultural cover on bat species richness and activity.

\subsection{Bat Response Variables}

\subsubsection{Acoustic Surveys}

We conducted acoustic surveys for echolocation calls to measure bat species richness and activity. In each landscape, two points were selected for bat acoustic surveys. To select these points we began by finding 6 potential points within the 46

central $1 \mathrm{~km}$ x 1 km landscapes using ArcGIS10 (ESRI Inc. 2011). Potential points were at least $200 \mathrm{~m}$ apart along field boundaries at least $50 \mathrm{~m}$ long, with at least $25 \mathrm{~m}$ of continuous boundary extending in opposite directions from the point. Points were also at 
least $50 \mathrm{~m}$ from any non-agricultural land use, and were at least $100 \mathrm{~m}$ from a road, significant water feature, or building. We then visited the landscapes and eliminated any potential points that no longer met these criteria, as land use had sometimes changed since the 2007 spatial data used for landscape selection. From the remaining potential points we randomly selected 2 as our acoustic survey points for that landscape.

We conducted acoustic surveys from May $23^{\text {rd }}$ to August $1^{\text {st }}, 2012$, the period when migratory species are present and nightly temperatures are high enough to support active foraging (Fenton 1992). We surveyed each landscape once over the course of the season, unless we experienced equipment failure, in which case we returned to the landscape later in the season. We generally surveyed two different landscapes per night, rotating through landscapes such that we avoided any possible correlation between survey date and landscape variables. If night-time temperature was expected to drop below $10^{\circ} \mathrm{C}$, or heavy precipitation was anticipated, we did not conduct surveys as these conditions are expected to reduce bat activity (Erkert 1982).

At each surveying point, we mounted an AR 125 Ultrasonic Receiver (Binary Acoustic Technology) on a tripod at a height of one metre, and connected it to a laptop running SPECT'R recording software (Binary Acoustic Technology). We protected receivers with rain-guards, and directed them 45 degrees towards a plexiglass sheet which reflected sound, equivalent to directing them 45 degrees towards the sky. We directed receivers parallel to the field boundary, and away from the nearest nonagricultural feature to minimize sound obstruction by trees or other landscape features, and thus maximize detectability (Fenton 1992, Kunz and Parsons 2009). We placed laptops in plastic bins to protect them. 
We set laptops to begin recording at sunset (ranged from $~ 20: 30$ to 21:00 during the study) for 3 hours. This is one of the peak foraging times for bats, and thus was likely to maximize encounter rates (Walsh et al. 2004). We programmed SPECT'R to record automatically for 20 seconds if a sound 10+ decibels above background noise and 15-120 $\mathrm{kHz}$ in frequency was detected. The recording ceased any time the sound stopped for 1 second or more. We selected these values to correspond to echolocation call attributes of local species (van Zyll de Jong 1985, Menzel et al. 2003).

\subsubsection{Bat Call Classification}

Bat calls consist of a rapid series of "chirps" emitted in quick succession; the entire sequence of chirps is referred to as a "call" or "pass". Calls are typically divided into two categories: "search-phase calls" and "feeding buzzes" (Kalko et al. 2001). During a search-phase call a bat is searching for potential prey and the interval between chirps is between 50 and 100 milliseconds (Griffin et al. 1960). Once a bat has acquired a target it will emit a feeding buzz which has a smaller interval ( $<10$ milliseconds), and varies depending on the target and context of pursuit (Griffin et al. 1960, Kalko et al. 2001). Analysis of the acoustic characteristics of search phase calls enables identification of many bat species (Fenton and Bell 1981) when other methods (e.g. physical capture, DNA analysis) are impractical, and allows determination of species presence and relative activity levels across sites (Walsh et al. 2004).

To identify the species of a call, we analyzed the acoustic parameters of the recorded chirps using a quadratic discriminate function analysis model (QDFA) created in Minitab 15 (2000) by Kevin Ethier (Ethier 2010). Discriminant Function Analysis (and 
its quadratic variant) is used to determine which variable combinations distinguish between already defined categories if enough known references from all categories are available. The measurements of these variables from unknown observations can then be entered into the model to determine its likely categorical classification. Ethier (2010)'s QDFA compares the acoustic parameters of unknown search phase chirps to a library of validated reference calls (Russo and Jones 2002), and provides a posterior probability (0$100 \%$ ) of the chirp belonging to each of the potential species in the model. Ethier (2010) created the QDFA using full-spectrum reference calls of local species from the Fenton Laboratory (Hooton and Adams, unpublished, University of Western Ontario). The recordings were of free-flying individuals recorded in various locations around Ontario including: P. subflavus $(\mathrm{n}=33)$, . septentrionalis $(\mathrm{n}=21)$, . lucifugus $(\mathrm{n}=68), L$. noctivagans $(\mathrm{n}=28)$, E. fuscus $(\mathrm{n}=51)$, L. borealis $(\mathrm{n}=29)$, and L. cinereus $(\mathrm{n}=39)$ (Ethier 2010). The acoustic characteristics used in the QDFA are chirp duration, interpulse interval, maximum frequency, minimum frequency, bandwidth, dominant frequency, characteristic frequency, slope, and curvature. The QDFA had an overall correct classification rate of $88.8 \%$ ( 239 of 269 reference calls correctly classified) (Ethier 2010). For each species expected in our study area, correct classification rates were: P. subflavus $87.9 \%$; M. septentrionalis $95.2 \%$; M. lucifugus $79.4 \%$; L. noctivagans 92.9\%; E. fuscus 90.2\%; L. borealis 93.1\%; and L. cinereus 94.9\% (Ethier 2010). We retained only recordings with 2 or more search-phase chirps to ensure the sound was part of a bat call and not due to other noise present in the landscape (Thomas 1988). We also visualized all recordings using SCAN'R and checked visually for irregularities. The search-phase chirp with the highest signal-to-noise ratio from each call 
was selected for identification to species (Parsons and Jones 2000). For each chirp the QDFA identified the most likely species along with a probability of correct classification. If a chirp's probability of correct identification was $\geq 95 \%$ this species was assigned to the call. For chirps with probabilities of correct identification 50-95\%, we classified the remaining chirps in the call using the QDFA. If there were at least twice as many chirps assigned to one species relative to any others, we assigned the call to that species. We categorized as "unidentified" any calls where the chirp with the highest signal-to-noise ratio had a probability of correct identification of $<50 \%$ and/or did not have at least 2 times as many chirps belonging to one species compared to any other species were categorized as "Unidentified" ( $\sim 6 \%$ of calls).

\subsection{Insect Trapping and Weather Monitoring}

We estimated activity of flying insects at each acoustic recording point during the night of recording as an index of relative food availability for that night. We sampled flying insects using custom made cylindrical sticky traps. Each trap consisted of a sheet of $33 \mathrm{~cm} \times 29.5 \mathrm{~cm}$ white paper secured around a PVC pipe mounted on an extendable pole $2 \mathrm{~m}$ high (Barclay 1985). The cylindrical shape prevents wind directionality from biasing sampling (Kunz 1988). We secured traps with 3 guy ropes staked into the ground, and then painted the paper with Tangletrap, a non-attractive paste to which flying insects adhere upon collision. We positioned traps along field boundaries $10 \mathrm{~m}$ behind the acoustic receiver (Figure 5).

Upon collection the following morning, other field crews wrapped cling film around the sticky portion of the trap to secure trapped insects for later inspection. We 
counted all insects, and divided them into size categories based on body length $(<10 \mathrm{~mm}$, $10 \mathrm{~mm}$ or larger, and $15 \mathrm{~mm}$ or larger) (Threlfall et al. 2012) and identified them to Order (Dipterans, Lepidoterans, Coleopterans, Hymenopterans, or Other).

At each landscape we chose the surveying point with the least obstruction to wind and erected a weather station (Ambient Weather WS-2080 Wireless Home Weather Stations) next to the insect trap, $10 \mathrm{~m}$ from the receiver. We programmed weather stations to record precipitation, temperature, and wind speed every 15 minutes during recording nights. Moonlight has been linked to changes in microhabitat use by insectivorous bats (Hecker and Brigham 1999), so we also recorded the percentage of moon illumination and the number of minutes the moon was above the horizon during surveying from local weather networks for each night. The product of these is an index of the moon illumination for the surveying period each night, however we were unable to account for cloud cover at individual landscapes.

\subsection{Statistical Analysis}

\subsubsection{Bat Response Variables}

For each bat acoustic survey point we calculated the number of species identified at that point (Species Richness), the total number of bat calls including unidentified calls (Total Activity), and the number of calls identified for each species (Species Activity). As all bat response variables except species richness showed evidence of overdispersion we used a negative binomial distribution in all models of total bat activity and species activity. We used zero-inflated models for the activity levels of all but the most 
commonly recorded species (E. fuscus, and L. cinereus), as other species were not recorded at a large number points.

\subsubsection{Selection of Confounding Variables for Inclusion in Landscape Models}

We excluded average rain and average wind during surveying from consideration since we observed little variation in these variables over the course of the study, likely because we specifically avoided surveying on nights when heavy precipitation or strong winds were anticipated. We examined the remaining potential confounding variables (date, average temperature, and moon illumination) for normality, using Shapiro-Wilk's tests.

To determine which confounding variables should be included in models of mean field size and Shannon Diversity of agriculture (below), we created generalized linear mixed models relating each bat response variable (species richness, total activity, and each species' activity) to all combinations of potential confounding variables (date, average temperature, and moon illumination) with landscape included as a random effect to control for repeated measures on the same landscape. We then ranked the models by AICc scores and included null models in this comparison (Burnham and Anderson 2003). If the null model was not in the top models $(\Delta \mathrm{AICc}<2)$, all potential confounding variables in the top models for a bat response were included in the models for that bat response in the analyses of landscape effects on Species Richness, Total Activity, and activity of each species (below).

\subsubsection{Modelling Landscape Effects}


We evaluated the effects of the landscape predictor variables using generalized linear mixed models. We examined all landscape variables (mean field size, Shannon Diversity of agriculture, and proportion agriculture at 1,2, and $3 \mathrm{~km}$ extents) for normality, using Shapiro-Wilk's tests. We log-transformed mean field size to normalize the data. We then standardized the landscape variables to estimate their relative effects (Smith et al. 2009, Grueber et al. 2011). For each bat response variable 3 models were created, one for each spatial scale $(1,2,3 \mathrm{~km})$. Each model contained all 3 landscape variables (log mean field size, Shannon Diversity of agriculture, proportion agriculture) at that scale plus potential confounding variables as indicated by the AICc selection, and landscape as a random effect. We also specified a zero-inflation parameter for L.noctivagans, M. septentrionalis, M. lucifugus, L. borealis, and $P$. subflavus as they were not encountered at a high number of points.

\subsubsection{Insect Analysis}

To investigate the role insects might play in any observed effects of mean field size and Shannon Diversity of agriculture on bats, we first determined which sizes or Orders of insects had the strongest positive relationship with bat richness, total bat activity, and activity of each species. We created the following categories of insect abundance: total insects, insects $10+\mathrm{mm}$ in length, and insects $15+\mathrm{mm}$ in length. We also analyzed abundance of each Order (Dipterans, Lepidopterans, Coleopterans, Hymenopterans, or Other) regardless of body length. We examined abundance of all categories of insects for normality, using Shapiro-Wilk's tests, and log-transformed them to normalize the data. We then examined Pearson correlations between each bat response 
variable (Species Richness, Total Activity, and activity of each species) and each category of insect. We then selected the category of insects which had the strongest positive correlation with bat Species Richness, Total Activity, and activity of each species, and examined correlations between this category and the landscape predictors (Log Mean Field Size, and Shannon Diversity of agriculture) at the 1, 2, and $3 \mathrm{~km}$ scales. We compared these correlations with the relationships observed between bat activity and richness and mean field size and Shannon Diversity of agriculture, to see if there was support for the idea that mean field size and Shannon Diversity of agriculture influenced bats through their influence on bat's prey.

To investigate whether landscapes with higher compositional heterogeneity provided more stable foraging resources for bats we divided landscapes into a group with "high" Shannon Diversity of agriculture (above the mean) or "low" Shannon Diversity of agriculture (below the mean). For each group we then calculated the coefficients of variation for total insects, and insect categories which were most strongly correlated with bat responses, and compared them.

We conducted all analyses in R version 3.1.2 using the MuMIn, MASS, and glmmADMB packages.

\section{Results}

We recorded 2,865 echolocation calls, of which 2,689 (93.9\%) were identified. The number of echolocation calls per survey point ranged from 0-214, with a mean of 26.28. Each of the 7 expected species were found in at least 13 of the 46 landscapes surveyed. Hoary bats (L. cinereus) were found in all of the landscapes, and made up the 
majority (53.4\%) of calls recorded. Species richness for each point ranged from $0-7$, with a mean of 2.85 .

We focused on the $3 \mathrm{~km}$ scale as it encompasses the average commuting distance between foraging and roosting habitat for all local bat species (Brigham 1991, Campbell et al. 1996, Menzel et al. 2003, Sparks et al. 2005, Elmore et al. 2005, Broders et al. 2006) and was the scale at which we observed the strongest bat responses to our landscape predictor variables. We also explored these relationships at the 1 , and $2 \mathrm{~km}$ scales, and the results were generally similar, but weaker (Appendix A).

The strength of correlations (absolute r-values) between landscape predictor variables and potential confounding variables ranged between 0.0229 and 0.2574 (Table 1). The strongest correlation was between average temperature and Shannon Diversity of agriculture $(r=0.2574)$. Log of Mean Field Size and Shannon Diversity of agriculture were negatively correlated $(r=-0.5625$, Table 1$)$. The Proportion of Agriculture in a landscape was strongly correlated with the log of mean field size $(r=0.7789)$, and more weakly with Shannon Diversity of agriculture $(r=-0.2925)$ (Table 1).

\subsection{Effects of Landscape Predictors}

The activity levels of 3 species of bat showed significant $(\mathrm{p}<0.05)$ or near significant $(\mathrm{p}<0.10)$ responses to log of mean field size. L. borealis and M. lucifugus activity levels both responded negatively to increasing field sizes, and L. noctivagans responded positively to increasing field sizes (Figure 6). We did not detect a significant effect of log mean field size on bat species richness or total bat activity. 
The total activity level of bats, and of four species of bats showed a positive response to Shannon Diversity of agriculture. L. noctivagans, and E. fuscus both showed significant positive responses to Shannon Diversity of agriculture (Figure 7). Total bat activity, and activity of $L$. cinereus, and activity of M. septentrionalis showed near significant $(\mathrm{p}<0.10)$ responses to Shannon Diversity of agriculture (Figure 7). We did not detect a significant effect of Shannon Diversity of agriculture on bat species richness.

The activity levels of 4 species of bat showed significant $(\mathrm{p}<0.05)$ responses to proportion of agricultural cover. Both Myotis species and L. borealis responded positively to increasing amounts of agriculture and L.noctivagans responded negatively to increasing amounts of agriculture sizes (Figure 8). We did not detect a significant effect of proportion of agriculture on bat species richness or total bat activity.

\subsection{Selection of Confounding Variables for Inclusion in Landscape Models}

No combination of the potential confounding variables (date, average temperature, or moon illumination) was found to be an improvement over the null model (which included only landscape identity to account for repeated measures on landscapes) for any bat response (Table 2). Therefore no potential confounding variables were included in models of bat responses to landscape predictor variables.

\subsection{Insect Analysis}


We trapped 2650 insects over 109 trap nights. Dipterans made up approximately $57.5 \%$ of the caught insects, followed by Coleopterans (16.7\%), Hymenopterans (5.0\%) and Lepidopterans (3.4\%). The remaining insects were not classifiable into one of these categories (e.g. Hemiptera). The vast majority of insects caught were under $10 \mathrm{~mm}$ long $(96.2 \%)$.

Of the insect categories we examined, the log of the number of moths had the strongest positive correlation with most bat response variables (Table 3). Exceptions to this were the activity levels of $L$. noctivagans, and $P$. subflavus which were more correlated with the number of insects $10+\mathrm{mm}$ long, and the activity levels of $M$. lucifugus, and E. fuscus which were more strongly correlated with the log of the number of beetles. Overall however, relationships between insects and bat responses were generally weak or negligible (absolute value of Pearson's $r<0.30$ ) All insect categories investigated had weak or negligible negative correlations with log of mean field size, and weak or negligible positive correlations with Shannon Diversity of agriculture (Table 4). The coefficients of variation of insect counts in various categories in landscapes with low Shannon Diversity of agriculture were all slightly higher than those in landscapes with high Shannon Diversity of agriculture (Table 5).

\section{Discussion}

We predicted that configurational heterogeneity would have a positive relationship with bat species richness and activity within a landscape (i.e. a negative relationship with the log of the mean field size) as a larger number of field boundaries within an agricultural landscape should increase its quality and accessibility for bats. This 
was, however, not well supported. Although reduced mean field sizes appeared to have a positive effect on the activity levels of two bat species (M. lucifugus, L. borealis), it also appeared to have a negative effect on L. noctivagans, and we did not detect a significant effect on bat species richness, total activity, or the activity levels of 4 other species.

These results are surprising because previous research indicates that bats are highly sensitive to the loss of field boundaries (Pocock and Jennings 2008), which can act as flight corridors, foraging habitat, and protection from wind or predators (Verboom and Huitema 1997). Insect abundance has also been shown to be higher along hedgerows than in fields (Gruebler et al. 2008), therefore we expected more field boundaries to provide higher quality foraging habitat.

It is possible that we did not detect more positive effects of reduced mean field size on bat activity because while bats may be more active along linear features, they will still forage in open areas within agriculture (Frey-Ehrenbold et al. 2013). Even at the lowest levels of configurational heterogeneity present in our study, there may still have been sufficient commuting and foraging corridors to allow these highly mobile species access to the agricultural landscape from their roosting habitat. While all local species are documented as most active along edges (Jantzen and Fenton 2013), this may not result in landscape scale effects of mean field size for all species. Indeed, for L. noctivagans, we observed a positive effect of mean field size.

We predicted that compositional heterogeneity would be positively related to bat species richness and activity, as different types of crops might support different insect communities representing more temporally stable foraging habitat. We found strong 
support for a generally positive response of bat activity to increasing Shannon Diversity of agriculture: it had a significant positive effect on total bat activity, and the activity of four species of bats, and had positive standardized coefficients for another 2 bat responses.. This relationship was strongest at the $3 \mathrm{~km}$ scale (Figure 7), but appeared fairly consistent across the other scales examined (Appendix A).

We suspect that this pattern is being driven by the relationship between prey insects and the diversity of crops, especially over time. Bats are known to track the abundances of specific prey insects (McCracken et al. 2012, Krauel et al. 2014) and may exploit certain crops during periods of high pest activity, and forage in other habitats during periods of low pest activity (Maine 2014). Landscapes with more diverse crops have peaks of insect prey at different times, and thus remain viable foraging areas despite time of growing season. The bat species in this region do not tend to heavily specialize on any specific taxa of insect (Anthony and Kunz 1977, van Zyll de Jong 1985, Menzel et al. 2003, Harvey et al. 2011) and so are able to prey upon a large number of species within agricultural landscapes. These flexible diets means that local bat species would be able to forage in landscapes with diverse communities of prey insects resulting from diverse crops.

We did find that all insect categories we investigated had weak or negligible positive correlations with Shannon Diversity of agriculture (Table 4). Although weak, the positive relationship between moths, beetles, and 10+ mm insects with Shannon Diversity of agricultural cover may support the argument that the positive relationships between total bat activity levels, activity levels of L. noctivagans, M. septentrionalis, L. cinereus, 
and E. fuscus, and Shannon Diversity of agriculture are due in part to the relationship between insects and Shannon Diversity of agriculture.

Similarly we found that landscapes with higher Shannon Diversity of agriculture had lower coefficients of variation for insect abundances. For insects $10 \mathrm{~mm}+$ long and moths, especially, there was approximately $25-30 \%$ more variation in counts within landscapes with above average Shannon Diversity of agricultural cover. This supports the idea that these landscapes may be less predictable foraging habitats for bats.

Correlations between semi-natural habitat, such as forests, and Shannon Diversity of agriculture did not likely influence our results, however crop type may play a role. There were apparent positive correlations between forest amount and bat species richness and some species activity levels within our study landscapes (Appendix C), but Shannon Diversity of agriculture did not appear to be correlated with forest amount $(\mathrm{r}=0.1684$, $\mathrm{p}>0.05$ ). However, it should be noted that reduced crop diversity and conversion of forest cover to agricultural cover are both common agricultural intensification practices (Tscharntke et al. 2005) and so crop diversity and forest cover may be correlated in typical agricultural systems. Shannon Diversity of agriculture and proportion of a landscape covered with pasture or hay were also positively correlated $(r=0.4018$, $\mathrm{p}<0.05$, and $\mathrm{r}=0.4514, \mathrm{p}<0.05$ respectively) and these cover types have been associated with higher microbat activity in Australian agricultural systems (Lentini et al. 2012).

We included the proportion of agricultural cover in landscape models of bat responses to control for any potential effects. Although the landscape selection procedure attempted to constrain the range of proportion of agricultural cover (Pasher et al 2013), a 
wide range of values for proportion of agricultural cover were present in our study landscapes (0.4-0.9 at 3km). We observed a positive effect of proportion of agriculture on the activity levels of 3 species (M. septentrionalis, M. lucifugus, and L. borealis) and a negative effect on the activity of $L$. noctivagans. This was surprising given that proportion of agriculture was highly correlated with mean field size, and mean field size appeared to have opposite effects on these species' activity levels. It is possible that agricultural cover represented better foraging habitat than the non-cropped landcover within our study landscapes, or alternatively that in landscapes with a greater proportion of agricultural cover, foraging activity was less likely to be concentrated around forested edges (Jantzen and Fenton 2013) where we specifically avoided surveying.

Acoustic studies of bats often require compromises between the number of sites which can be surveyed, and the precision of data that can be obtained from each site (Fischer et al. 2009). Sampling in more locations per landscape, and/or more times per landscape across the season would also allow a more direct investigation into how the relationship between insect communities and Shannon Diversity of agriculture affects bat species richness and bat activity. Due to logistical constraints, however, we were unable to survey most landscapes repeatedly throughout the growing season, and were only able to survey at 2 points per landscape. This meant we were unable to specifically test our hypothesized mechanism responsible for the relationship observed between bat activity levels and Shannon Diversity of agriculture. That stated, we observed a consistent link between Shannon Diversity of agriculture and the activity levels of most bat species studied. 
Our results add to the current understanding of how agricultural landscape structure influences bat communities in that we tested the effects of the heterogeneity of cropped land, not the heterogeneity of semi-natural habitat. Lentini et al (2012) examine the influences of different types of crops on bat communities in Australia, however we are aware of no similar studies in North American agriculture. There has been some research into the effects of organic vs. conventional farming methods on bats (Wickramasinghe et al. 2003, Fuller et al. 2005, Davy et al. 2007) and their prey (Wickramasinghe and Harris 2004); however, these have shown inconsistent effects and do not generally take landscape heterogeneity into account. Similarly, most agrienvironmental schemes which compensate farmers for adopting certain farming practices, do not take landscape heterogeneity into account at a scale meaningful for bats (FuentesMontemayor et al. 2011).

\subsection{Implications}

Our findings can be used to inform farm management decisions by farmers and agricultural policy makers, especially considering the potential increase in pest removal services provided by bats. The scale at which we found the strongest effect of Shannon Diversity of agriculture was $3 \mathrm{~km}$, which means that even single large farms, or small groups of neighboring farms (e.g. neighbouring farms run by family members) in this region can effectively make these management decisions. In Figure 9 we give an example of a typical landscape from the lowest and highest quartiles of Shannon Diversity of agriculture observed in our study, as well as the mean of bat responses for these two quartiles of landscapes in our study. For several bat species, landscapes with higher 
Shannon Diversity of agriculture appear to have on average approximately 1 more species, almost twice as much total bat activity, and from 1.5-20 times more activity of individual species.

Diversified crops are associated with lower densities of pest insects (Tonhasca and Byrne 1994), and so increasing the compositional heterogeneity of agricultural landscapes may reduce pest densities in additional ways beyond increasing bat activity levels. As well, the pest removal services of birds appear to be additive to those of bats (Williams-Guillén et al. 2008), so by combining our recommendations with bird management guidelines it may be possible to maximize pest removal services from both these taxa. When generalist predators, such as bats in this region, have a consistent supply of food, they can be more effective in suppressing outbreaks of pest species, as they can maintain higher populations even when specific pest numbers are lower (Symondson et al. 2002). By increasing the diversity of crops within agricultural landscapes, farmers can help promote bat activity, and related pest removal.

Given our results, and other studies on bat activity patterns in agriculture, we suggest bat activity in agricultural landscapes can be promoted through planting diverse crop types including pasture and hay, and maintaining or creating interspersed forest fragments, vegetated field margins, and scattered trees (e.g.Figure 10). We demonstrate that Shannon Diversity of agricultural cover is positively associated with the activity levels of several local bat species, as well as total bat activity, and while North American studies are lacking Lentini et al. (2012) have shown that pasture is a key cover type in promoting bat activity in Australian agroecosystems. Forest is necessary to provide roosting habitat, and forest-field edges are areas of high bat activity (Jantzen and Fenton 
2013). The activity levels of several local bats are also higher in landscapes with increased fragmentation (but not loss) of forest habitat (Ethier and Fahrig 2011) and bats may select roosts near forest edges to reduce commuting costs (O'Keefe et al. 2009). Although we did not find a strong positive effect of reduced mean field size on bat activity, there are multiple other studies which suggest that field margins provide multiple benefits to bats (Limpens et al. 1989, Verboom and Huitema 1997, Boughey et al. 2011, Lentini et al. 2012, Frey-Ehrenbold et al. 2013). Similarly, Fisher et al (2010), and Lentini et al. (2012) both find that scattered trees within agricultural landscapes have a disproportionately positive effect on bat activity, even in low numbers. Applying these guidelines to agricultural landscapes is perhaps most important in intensively farmed areas, to mitigate high intensity management and improve pest regulation (Weilbull and Ostman 2003, Tscharntke et al. 2005, Bianchi et al. 2006).

\subsection{Conclusions}

Based on our findings we recommend that farmers or agricultural organizations seeking to increase bat activity on farms without removing land from production focus on increasing the diversity of crops at $3 \mathrm{~km}$ or larger scales. Overall bat activity (especially of certain species) is higher in landscapes with higher diversity of agricultural crop cover. We hypothesize this is likely because diverse crops, including hay and pasture, create more temporally stable insect food resources. 


\section{Tables}

Table 1: Pearson correlations between potential confounding variables on bat species richness, total activity, and activity levels of individual species and landscape variables at $3 \mathbf{k m}$ scale in agricultural study landscapes in Eastern Ontario

\begin{tabular}{lccccc}
\hline & $\begin{array}{c}\text { Average } \\
\text { Temperature }\end{array}$ & $\begin{array}{c}\text { Moon } \\
\text { Illumination }\end{array}$ & $\begin{array}{c}\text { Log MFS } \\
(3 \mathrm{~km})\end{array}$ & $\begin{array}{c}\text { SHDI } \\
(3 \mathrm{~km})\end{array}$ & $\begin{array}{c}\text { Proportion } \\
\text { Agriculture }(3 \mathrm{~km})\end{array}$ \\
\hline Date & -0.0196 & 0.1245 & -0.0229 & 0.1138 & 0.0792 \\
Average Temperature & & -0.3071 & -0.1369 & 0.2574 & -0.0434 \\
Moon Illumination & & & 0.1917 & -0.1583 & 0.1651 \\
Log MFS (3km) & & & -0.5625 & 0.7789 \\
SHDI (3km) & & & & -0.2925 \\
\hline
\end{tabular}


Table 2: Top models of all combinations of potential confounding variables of bat responses ranked by AICc. Null models included only landscape identity as a random effect term to account for repeated measures on landscapes.

\begin{tabular}{|c|c|c|c|c|c|c|}
\hline Response & Model & df & $\log$ Lik & $\mathrm{AICc}$ & delta & weight \\
\hline \multicolumn{7}{|c|}{ Species Richness } \\
\hline & Null & 2 & -179.128 & 362.4 & 0 & 0.4 \\
\hline & Average Temperature & 3 & -179.045 & 364.4 & 1.97 & 0.149 \\
\hline
\end{tabular}

Total Activity

Null

Average Temperature

Moon Illumination

Date

$\begin{array}{ccccc}3 & -402.23 & 810.7 & 0 & 0.312 \\ 4 & -401.751 & 812 & 1.22 & 0.169 \\ 4 & -401.911 & 812.3 & 1.54 & 0.144 \\ 4 & -402.02 & 812.5 & 1.76 & 0.129\end{array}$

L. noctivagans
Average Temperature

Moon

Moon + Average Temperature

Null

Date + Average Temperature

Date + Moon Illumination +

Average Temperature

$\begin{array}{ccccc}5 & -79.243 & 169.2 & 0 & 0.251 \\ 5 & -79.65 & 170 & 0.81 & 0.168 \\ 6 & -78.522 & 170 & 0.84 & 0.165 \\ 4 & -80.963 & 170.4 & 1.21 & 0.138 \\ 6 & -78.964 & 170.9 & 1.72 & 0.106 \\ 7 & -78.316 & 171.9 & 2.77 & 0.063\end{array}$

M. septentrionalis

Null

Moon Illumination

$\begin{array}{lllll}4 & -57.818 & 124.1 & 0 & 0.428\end{array}$

$\begin{array}{lllll}5 & -57.743 & 126.2 & 2.08 & 0.151\end{array}$

M. lucifugus
Null

Moon

Date + Moon Illumination

Average Temperature

Date

$\begin{array}{rrrcc}3 & -141.62 & 289.5 & 0 & 0.262 \\ 4 & -140.529 & 289.5 & 0 & 0.262 \\ 5 & -140.251 & 291.2 & 1.68 & 0.113 \\ 4 & -141.486 & 291.4 & 1.91 & 0.101 \\ 4 & -141.498 & 291.4 & 1.94 & 0.1\end{array}$


L. cinereus

$$
\begin{aligned}
& \text { Null } \\
& \text { Date }
\end{aligned}
$$

Moon Illumination

L. borealis

Null

Average Temperature

Moon Illumination

E. fuscus

Null

Average Temperature

Moon Illumination

P. subflavus

$\begin{array}{ccccc}3 & -347.139 & 700.5 & 0 & 0.345 \\ 4 & -346.795 & 702 & 1.49 & 0.163 \\ 4 & -346.846 & 702.1 & 1.6 & 0.155\end{array}$

$\begin{array}{lllll}4 & -96.254 & 201 & 0 & 0.285\end{array}$

$\begin{array}{lllll}5 & -95.296 & 201.3 & 0.32 & 0.243\end{array}$

$\begin{array}{lllll}5 & -95.888 & 202.5 & 1.5 & 0.134\end{array}$

$\begin{array}{lllcc}3 & -257.093 & 520.5 & 0 & 0.286 \\ 4 & -256.075 & 520.6 & 0.15 & 0.266 \\ 4 & -256.996 & 522.4 & 1.99 & 0.106\end{array}$

$\begin{array}{lllll}4 & -256.996 & 522.4 & 1.99 & 0.106\end{array}$

$\begin{array}{lccccc}\text { Moon Illumination } & 5 & -76.984 & 164.6 & 0 & 0.262 \\ \text { Date + Moon Illumination } & 6 & -76.27 & 165.5 & 0.86 & 0.171 \\ \text { Null } & 4 & -78.561 & 165.6 & 0.92 & 0.165 \\ \text { Date } & 5 & -77.578 & 165.8 & 1.19 & 0.145 \\ \begin{array}{l}\text { Moon Illumination + Average } \\ \text { Temperature }\end{array} & 6 & -76.891 & 166.7 & 2.1 & 0.092\end{array}$


Table 3: Pearson correlations of bat responses and abundances of different size and taxonomic categories of insects trapped during acoustic surveys for bats in agricultural landscapes in Eastern Ontario

\begin{tabular}{|c|c|c|c|c|c|c|}
\hline Bat Response & $\begin{array}{c}\text { Log } \\
\text { Beetles }\end{array}$ & $\begin{array}{l}\text { Log } \\
\text { Moths }\end{array}$ & $\begin{array}{l}\text { Log } \\
\text { Flies } \\
\end{array}$ & $\begin{array}{c}\text { Log Insects } \\
10+\mathrm{mm}\end{array}$ & $\begin{array}{c}\text { Log Insects } \\
15+\mathrm{mm}\end{array}$ & $\begin{array}{c}\text { Log Total } \\
\text { Insects }\end{array}$ \\
\hline $\begin{array}{c}\text { Species } \\
\text { Richness }\end{array}$ & -0.0287 & 0.2206 & -0.2006 & 0.1011 & 0.137 & -0.0632 \\
\hline Total Activity & 0.1598 & 0.2061 & -0.0392 & -0.0009 & 0.1139 & -0.0574 \\
\hline L. noctivagans & -0.0533 & 0.0138 & -0.0071 & 0.0398 & 0.0175 & -0.0139 \\
\hline $\begin{array}{c}M . \\
\text { septentrionalis }\end{array}$ & 0.0273 & 0.0748 & -0.1235 & -0.0177 & 0.0352 & -0.0321 \\
\hline M. lucifugus & 0.2028 & 0.1029 & -0.0344 & -0.0009 & 0.1195 & 0.0924 \\
\hline L. cinereus & 0.1416 & 0.2554 & -0.0135 & 0.0139 & 0.1114 & -0.1274 \\
\hline L. borealis & 0.0466 & 0.0677 & -0.0939 & -0.051 & -0.0121 & -0.1067 \\
\hline E. fuscus & 0.1353 & 0.0827 & -0.0465 & -0.0288 & 0.0828 & 0.0257 \\
\hline P. subflavus & -0.1273 & 0.0021 & -0.2121 & 0.0031 & -0.0113 & -0.0461 \\
\hline
\end{tabular}


Table 4: Pearson correlations between landscape predictor variables in agricultural Eastern Ontario study landscapes and the abundance of insects from size and taxonomic categories of insects most highly correlated with bat species richness and activity responses during acoustic surveys.

\begin{tabular}{lccc}
\hline Landscape Predictor & Log Beetles & Log Insects 10+ mm & Log Moths \\
\hline Log MFS $(3 \mathrm{~km})$ & -0.0889 & -0.0893 & -0.1713 \\
SHDI $(3 \mathrm{~km})$ & 0.0887 & 0.2289 & 0.2192 \\
PCTAG $(3 \mathrm{~km})$ & -0.0446 & -0.0446 & -0.0348 \\
\hline
\end{tabular}


Table 5: Coefficients of variation of insect totals for total insects, as well as size and taxonomic categories of insects most highly correlated with bat species richness and activity responses during acoustic surveys

\begin{tabular}{lcccc}
\hline & Total Insects & Insects $10 \mathrm{~mm}+$ & Total Moths & Total Beetle \\
\hline Low SHDI 3km & 86.71 & 144.02 & 200.02 & 151.57 \\
High SHDI 3km & 83.76 & 115.09 & 153.18 & 150.06
\end{tabular}




\section{Figures}
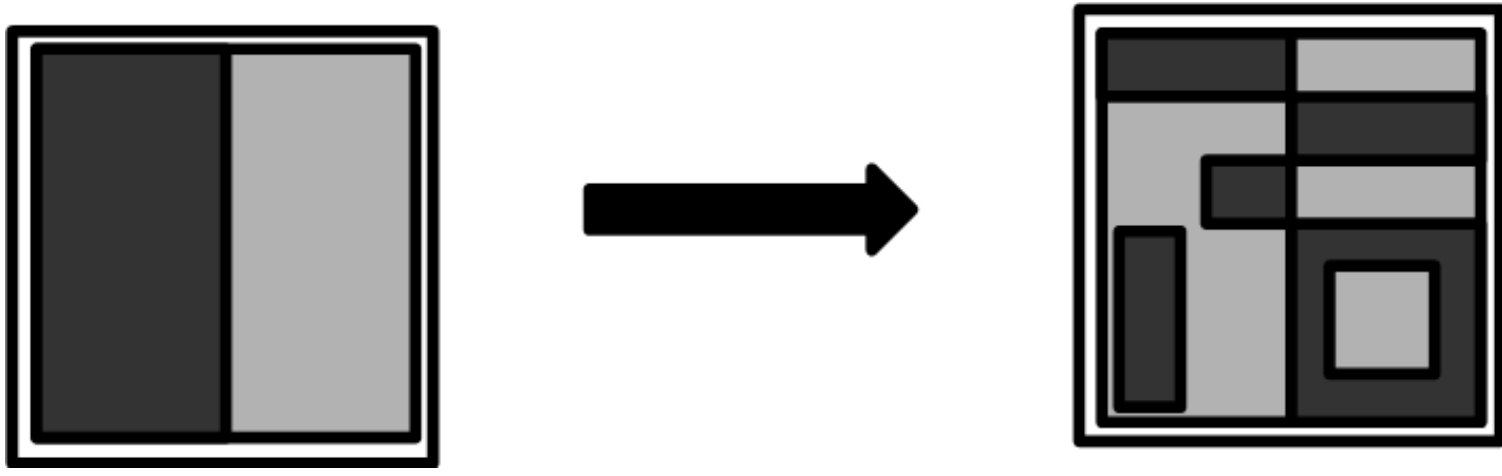

Figure 1: Increasing configurational heterogeneity independent of

compositional heterogeneity - each shade of grey represents a different crop type.

The landscape on the right has higher configurational heterogeneity, but both

landscapes have the same amount of each crop type (same compositional heterogeneity).
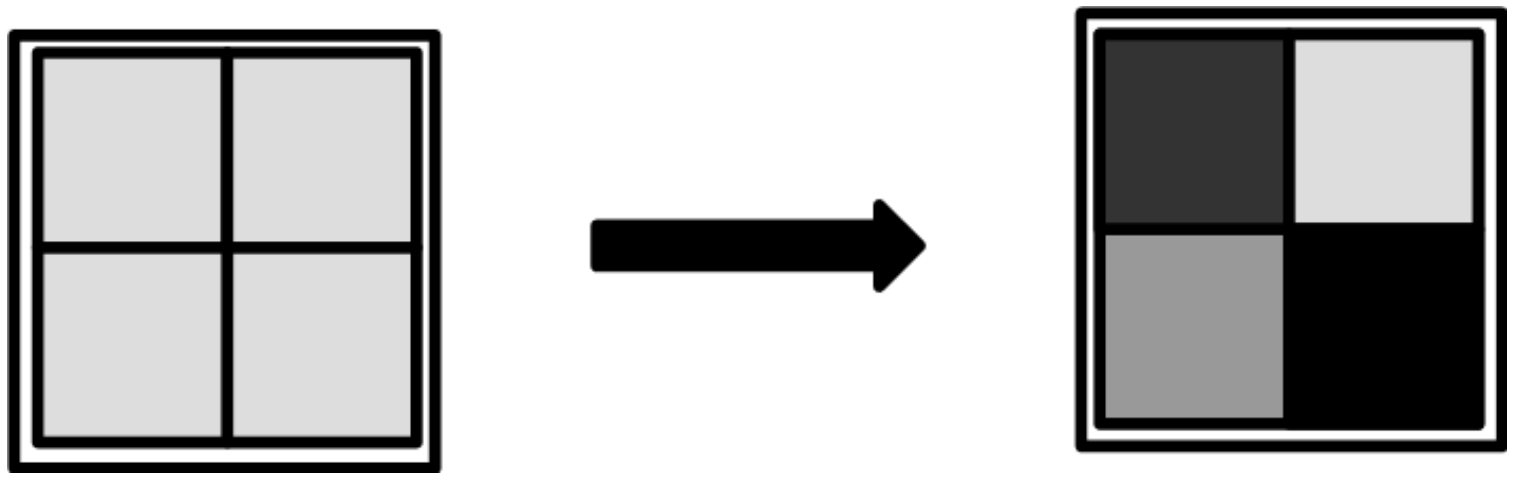

Figure 2: Increasing compositional heterogeneity independent of configurational heterogeneity - each shade of grey represents a different crop type. The landscape on the right has higher compositional heterogeneity, but both have the same 4 field layout (same configurational heterogeneity). 

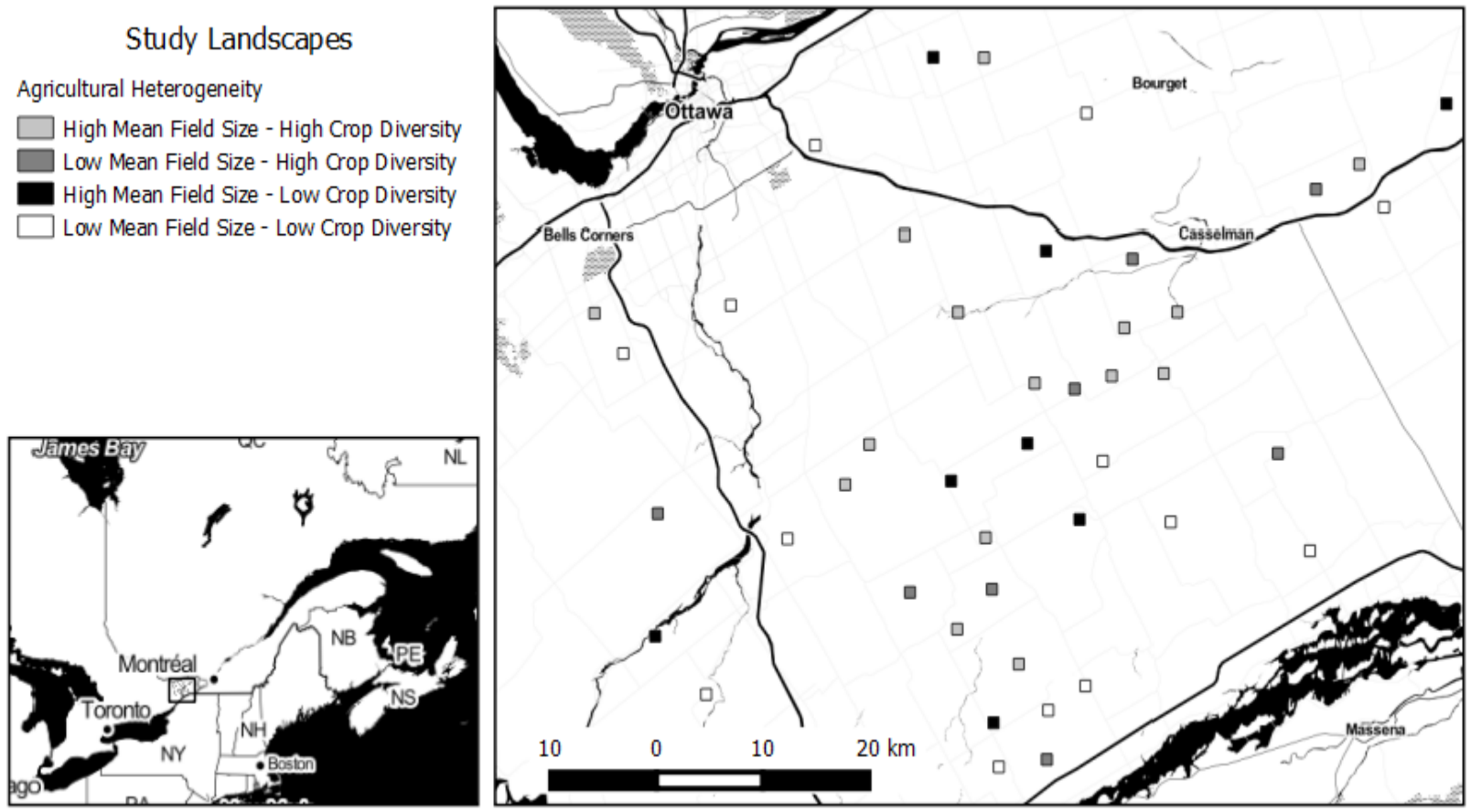

Figure 3: Location of study landscapes within agricultural Eastern Ontario.

Mean field size (LogMFS) and Shannon Diversity of agriculture (SHDI) existed on a continuous scale but were categorized as "High" or "Low" to allow rotation of sampling effort to avoid correlation of these categories with date. Landscapes here are represented at the $1 \mathrm{~km} \times 1 \mathrm{~km}$ scale. 


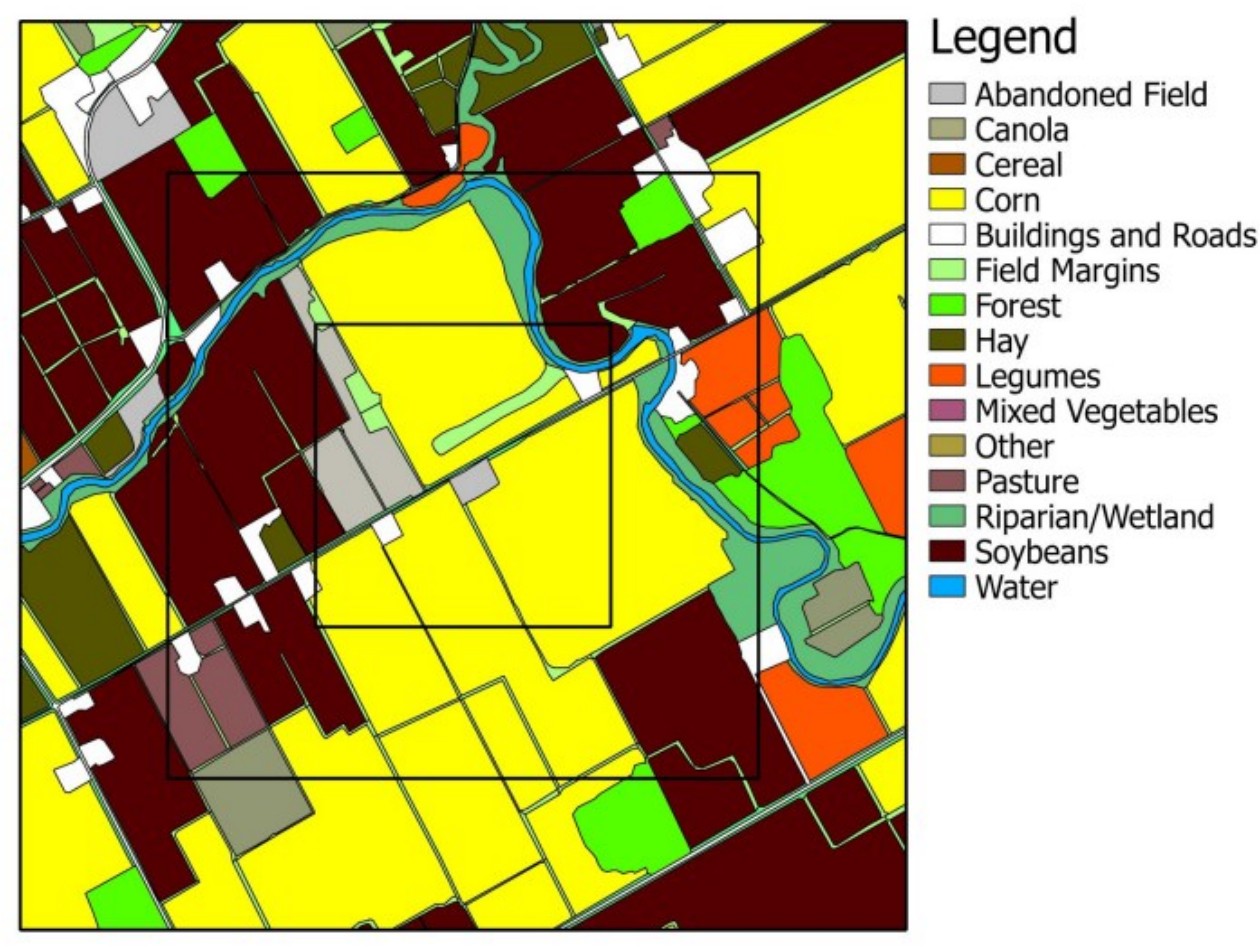

Figure 4: Example of agricultural study landscape with different land uses

mapped at 3 spatial extents (inner square $=1 \mathrm{~km} \times 1 \mathrm{~km}$, middle square $=2 \mathrm{~km} \times 2$ km, outer square $=3 \mathbf{k m} \times 3 \mathbf{k m})$. 


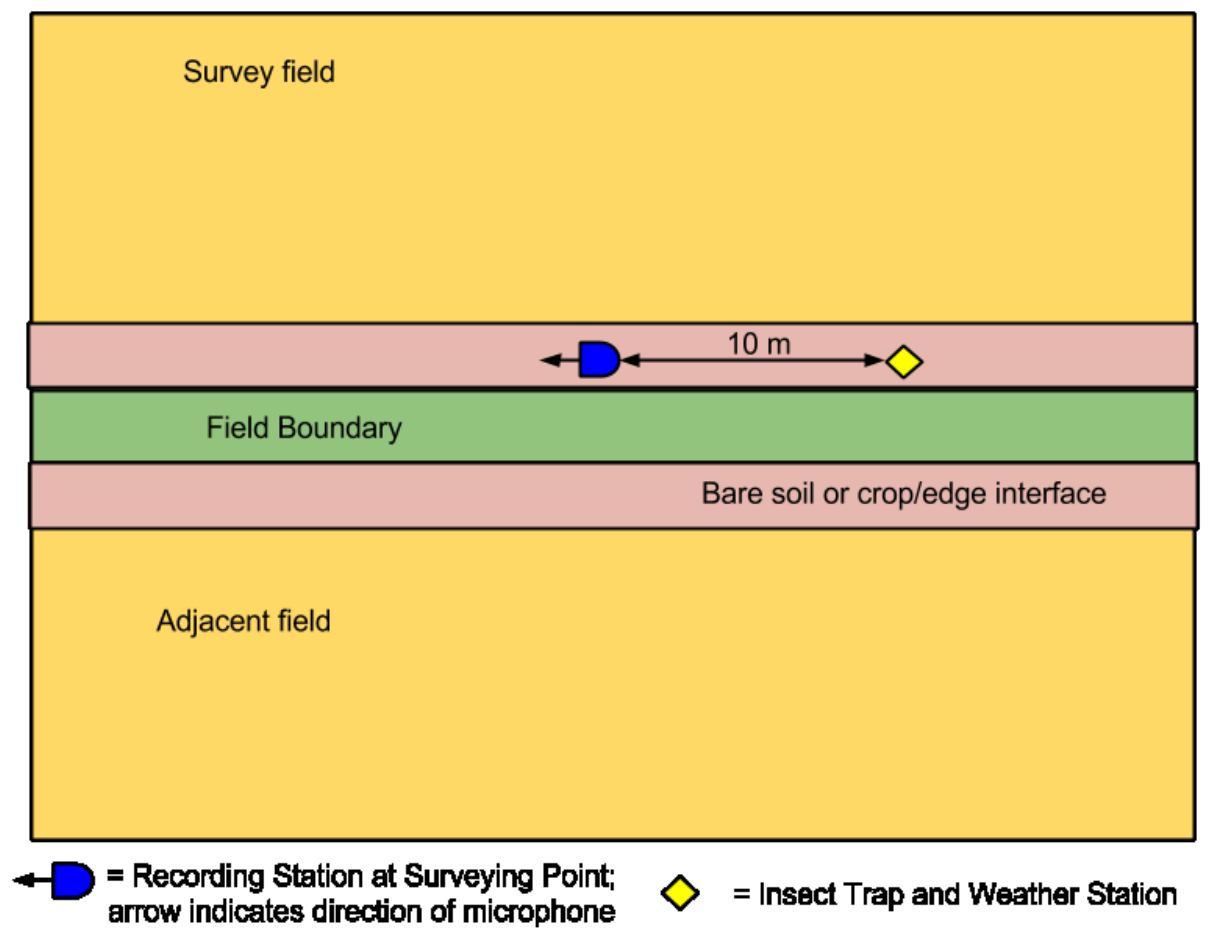

Figure 5: Diagram of layout of sampling equipment at each acoustic survey point, including bat recording station, and weather station/insect trap set up along field boundaries. 


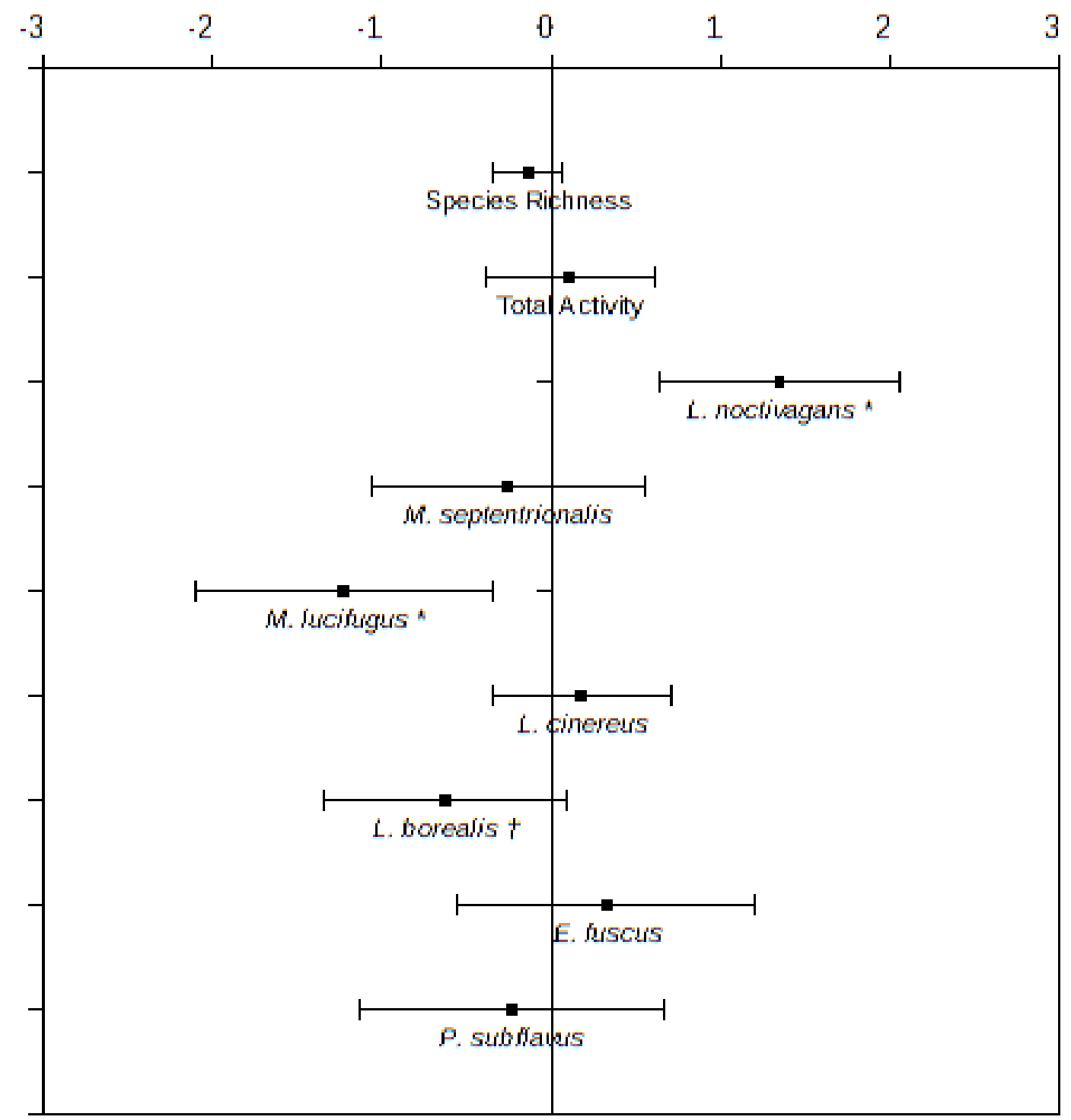

Figure 6: Standardized coefficients of Log Mean Field Size at $3 \mathrm{~km}$ in generalized mixed models of bat responses to landscape predictor variables (error bars show $95 \%$ confidence intervals, * indicates a p-value of $<0.05, \dagger$ indicates $p$ value of $<\mathbf{0 . 1 0})$ 


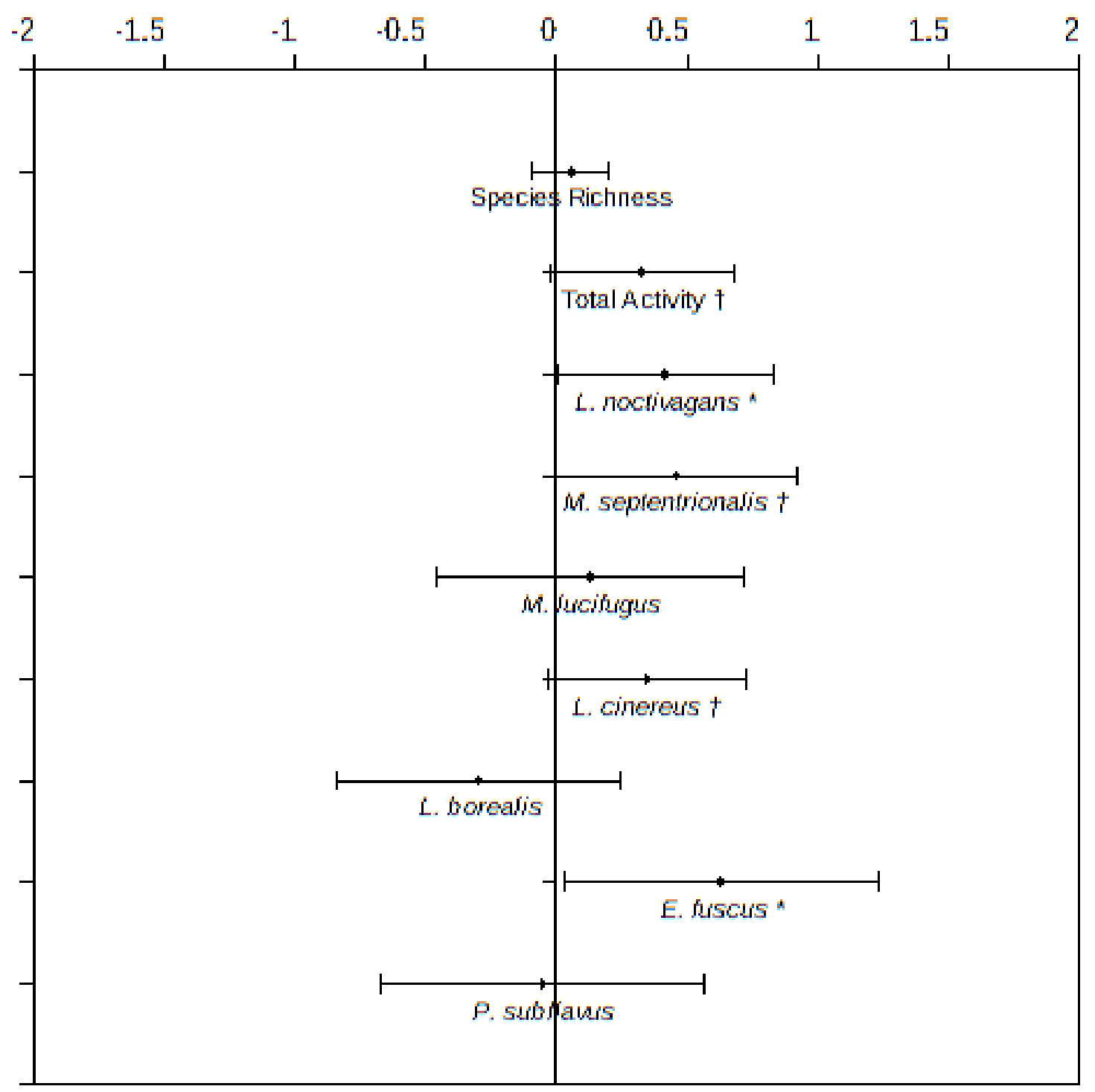

Figure 7: Standardized coefficients of Shannon Diversity of agriculture at

$3 \mathrm{~km}$ in generalized mixed models of bat responses to landscape predictor variables (error bars show 95\% confidence intervals, * indicates a p-value of $<0.05, \uparrow$ indicates $p$-value of $<\mathbf{0 . 1 0}$ ) 


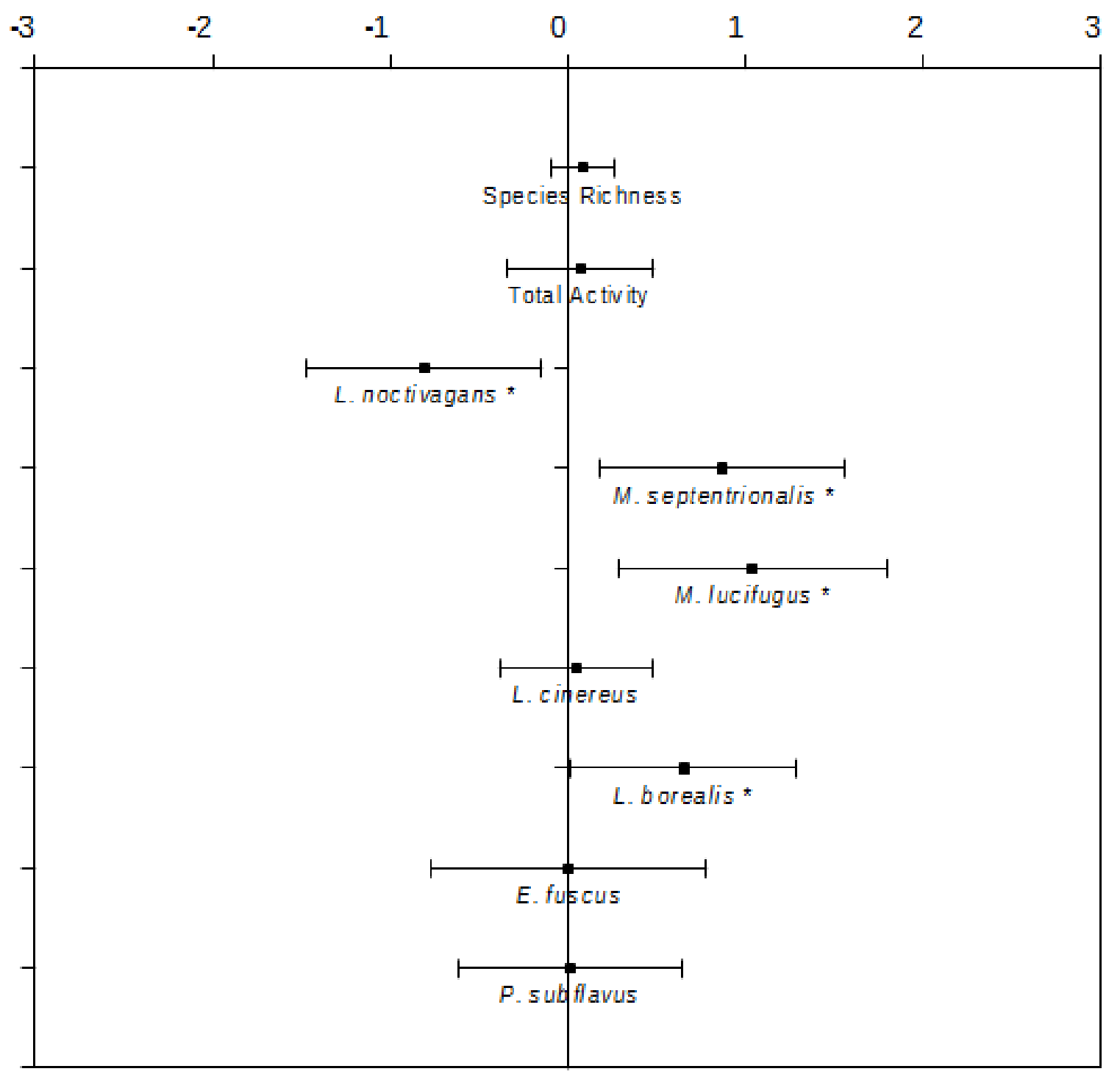

Figure 8: Standardized coefficients of Proportion of Agricultural Cover at 3

$\mathrm{km}$ in generalized mixed models of bat responses to landscape predictor variables (error bars show $95 \%$ confidence intervals, * indicates a p-value of $<0.05, \uparrow$ indicates p-value of $<0.10$ ) 

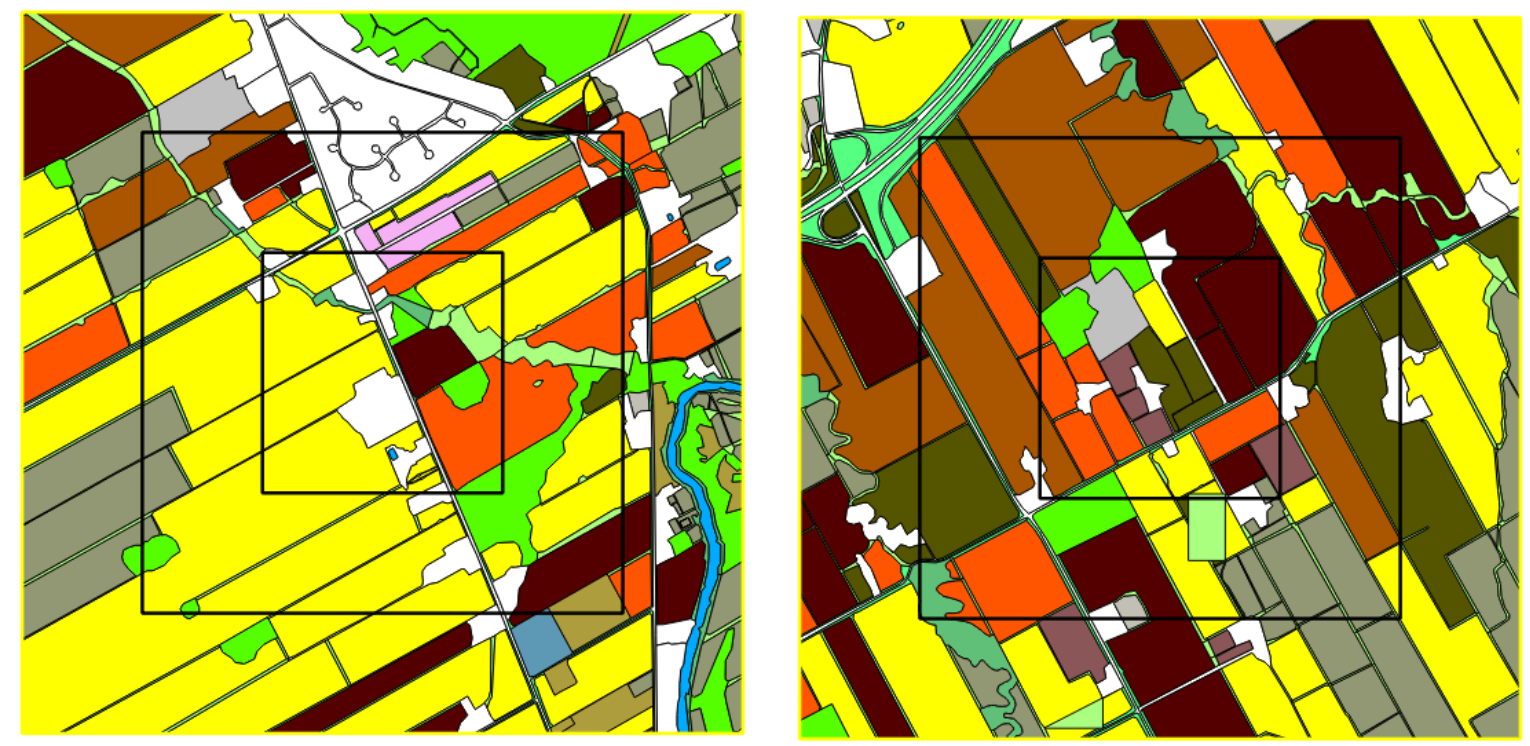

Legend

$\square$ Abandoned Field

$\square$ Canola

- Cereal

$\square$ Corn

$\square$ Buildings and Roads

$\square$ Field Margins

$\square$ Forest

- Hay

$\square$ Legumes

Mixed Vegetables

$\square$ Other

- Pasture

$\square$ Riparian/Wetland

- Soybeans

$\square$ Water

\begin{tabular}{lcc}
\hline & $\begin{array}{c}\text { Mean in Lowest Quartile } \\
\text { of SHDI 3km }\end{array}$ & $\begin{array}{c}\text { Mean in Highest Quartile } \\
\text { of SHDI 3km }\end{array}$ \\
\hline SHDI 3km & 1.05 & 1.59 \\
Species Richness & 2.37 & 3.36 \\
Total Activity & 19.63 & 37.14 \\
L. noctivagans & 0.74 & 0.68 \\
M. septentrionalis & 0.26 & 0.54 \\
M. lucifugus & 0.15 & 3.04 \\
L. cinereus & 11.52 & 19.39 \\
L. borealis & 0.44 & 0.43 \\
E. fuscus & 4.19 & 11.04 \\
P. subflavus & 0.30 & 0.46
\end{tabular}

Figure 9: Examples of agricultural cover in typical landscape in the lowest quartile of Shannon Diversity of agriculture (left) and the highest quartile of Shannon Diversity of Agriculture (right), and means of bat responses observed in landscapes within these quartiles 


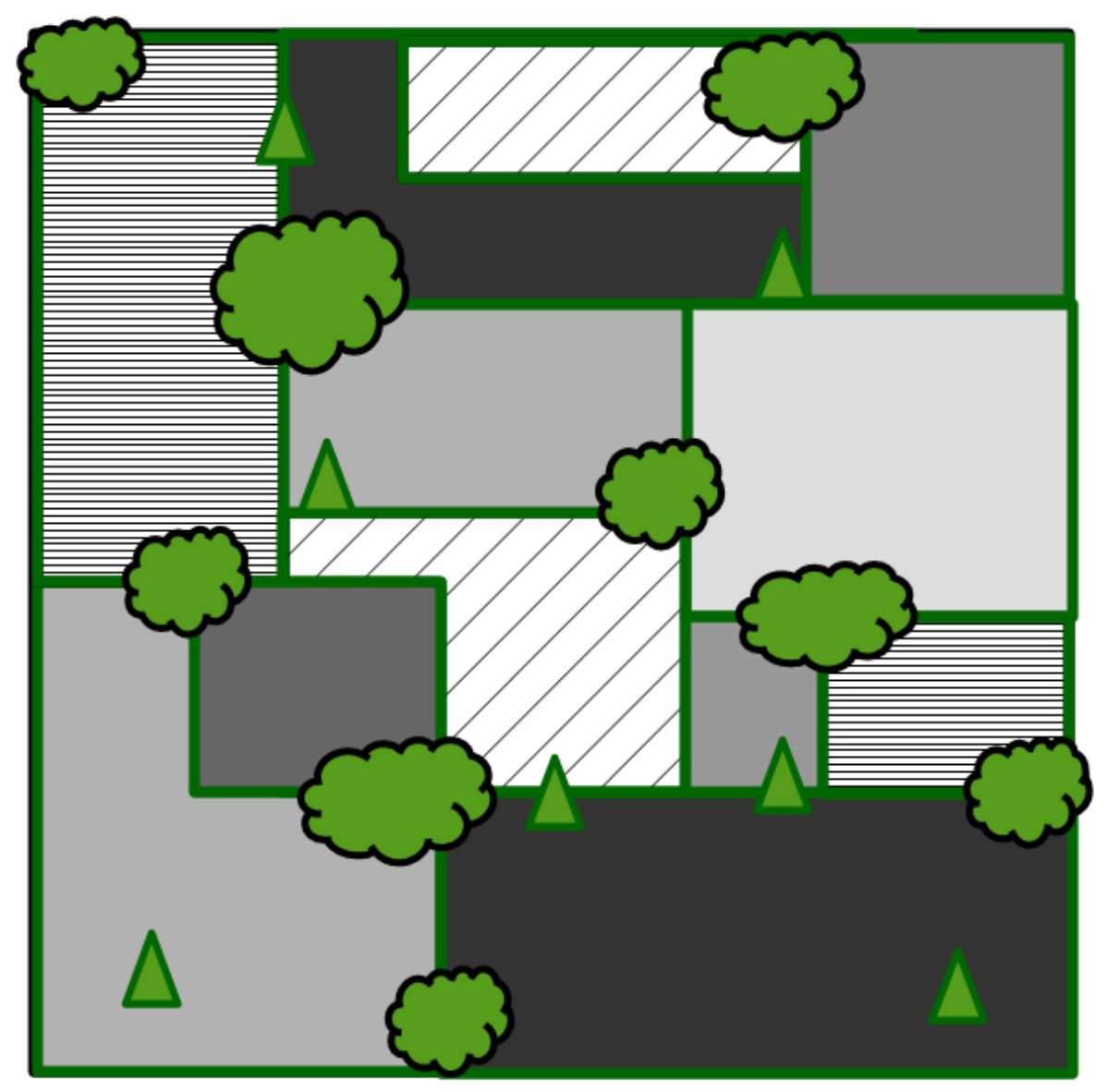

Figure 10: Example of theoretical agricultural landscape which promotes bat activity. Agricultural land use is indicated by grey or cross hatching, while natural and semi-natural land use is indicated in green. Different shades of grey represent different crop types, with horizontal hatching representing hay, while diagonal hatching represents pasture. Forest fragments are indicated by rounded green areas, and at least one is adjacent to each field. Individual scattered trees are indicated by green triangles. Field margins have semi-natural vegetation such as grass, shrubs, and brush. 


\section{Appendices}

Appendix A Standardized coefficients of landscape variables at 1, 2, and 3km scales in GLMM models of bat responses 

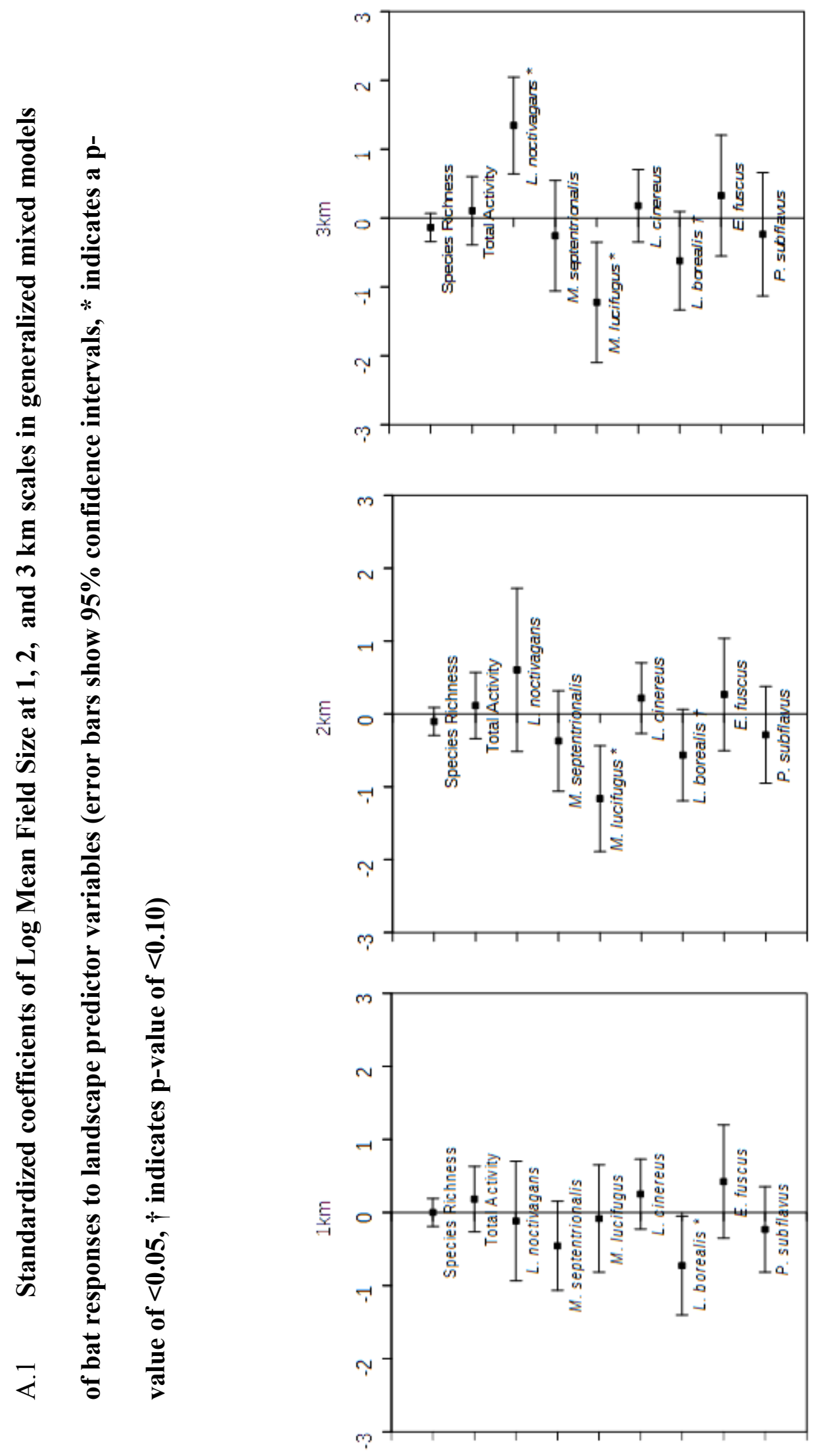

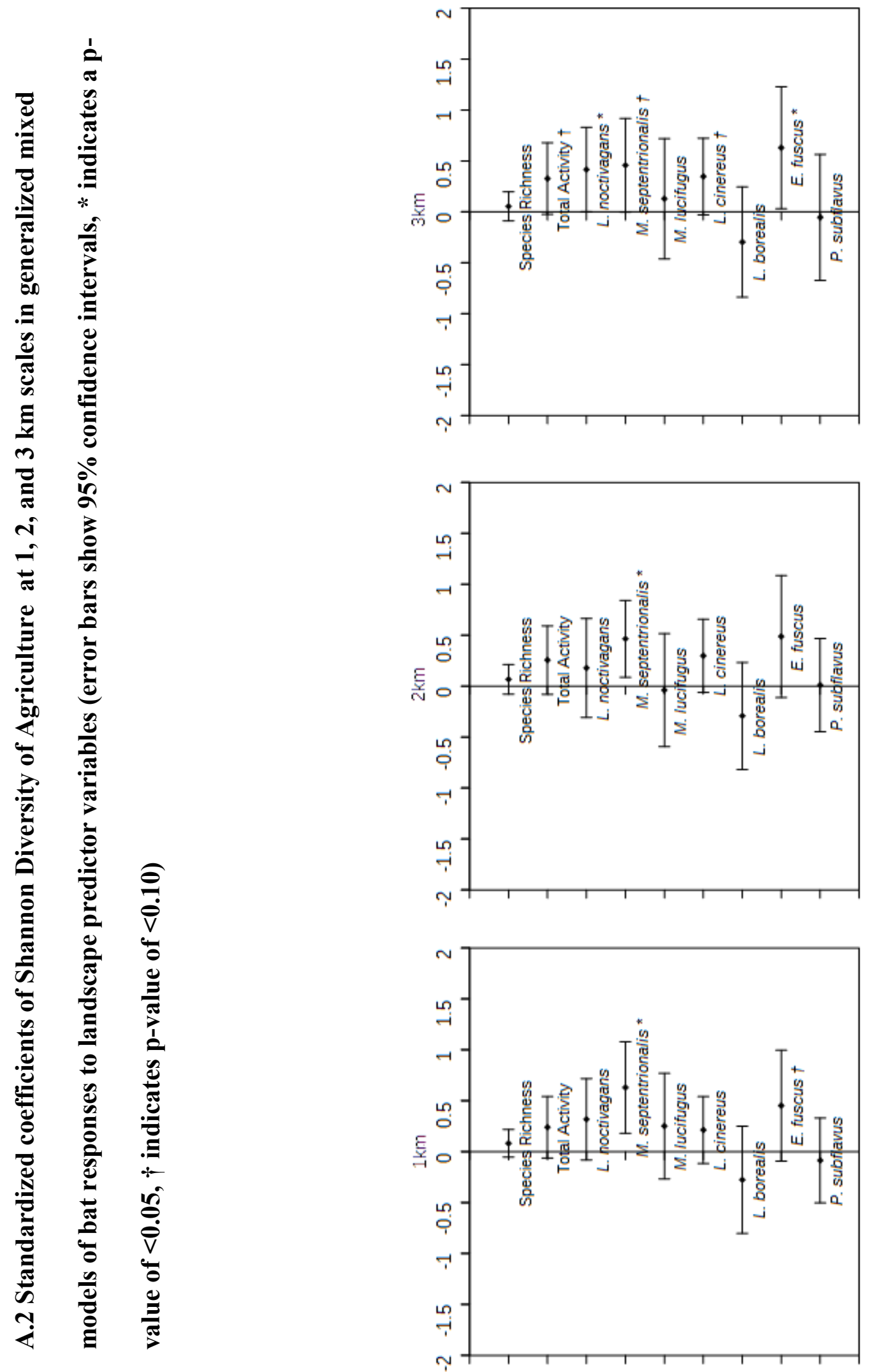

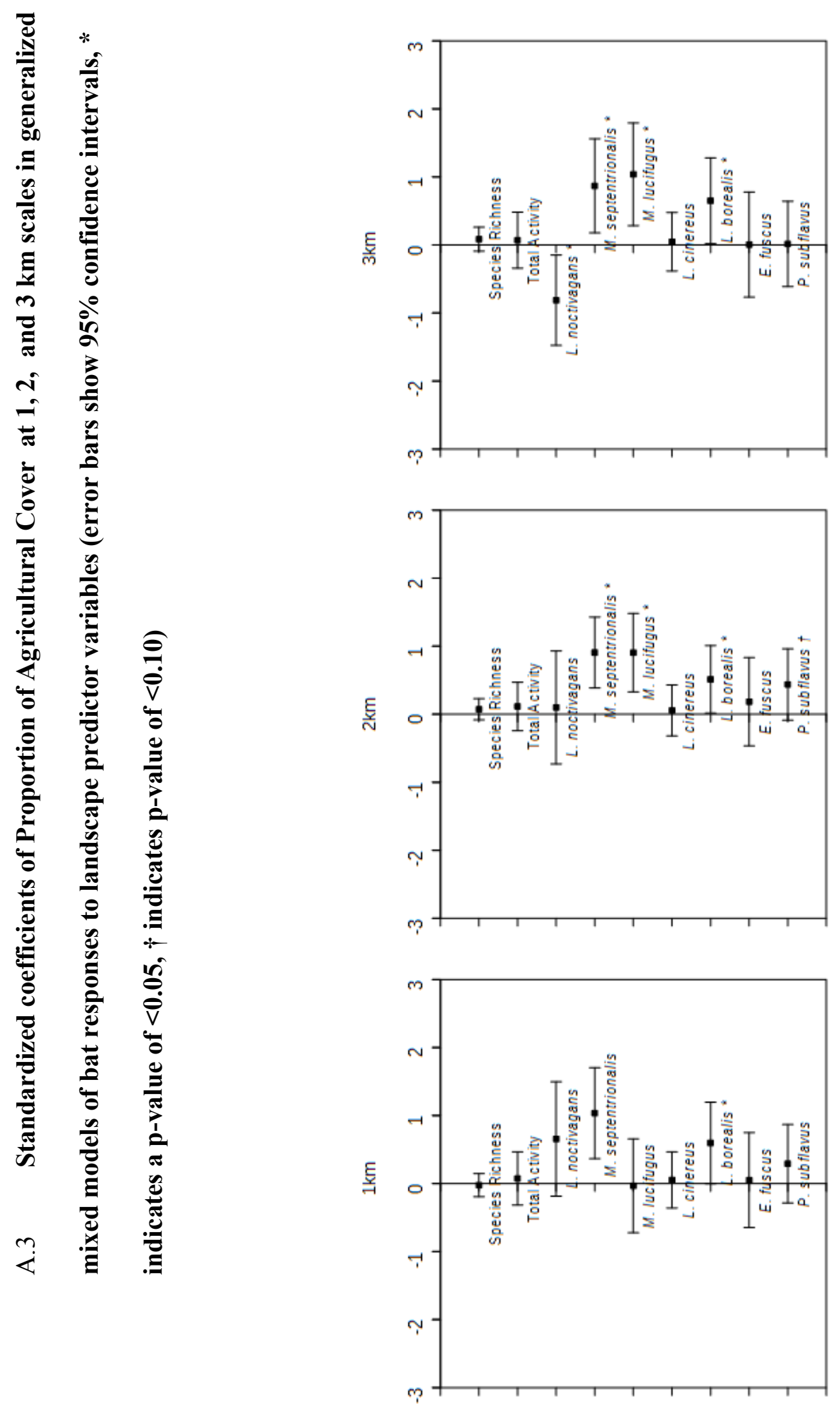
Appendix B Correlations between bat responses and landscape variables 

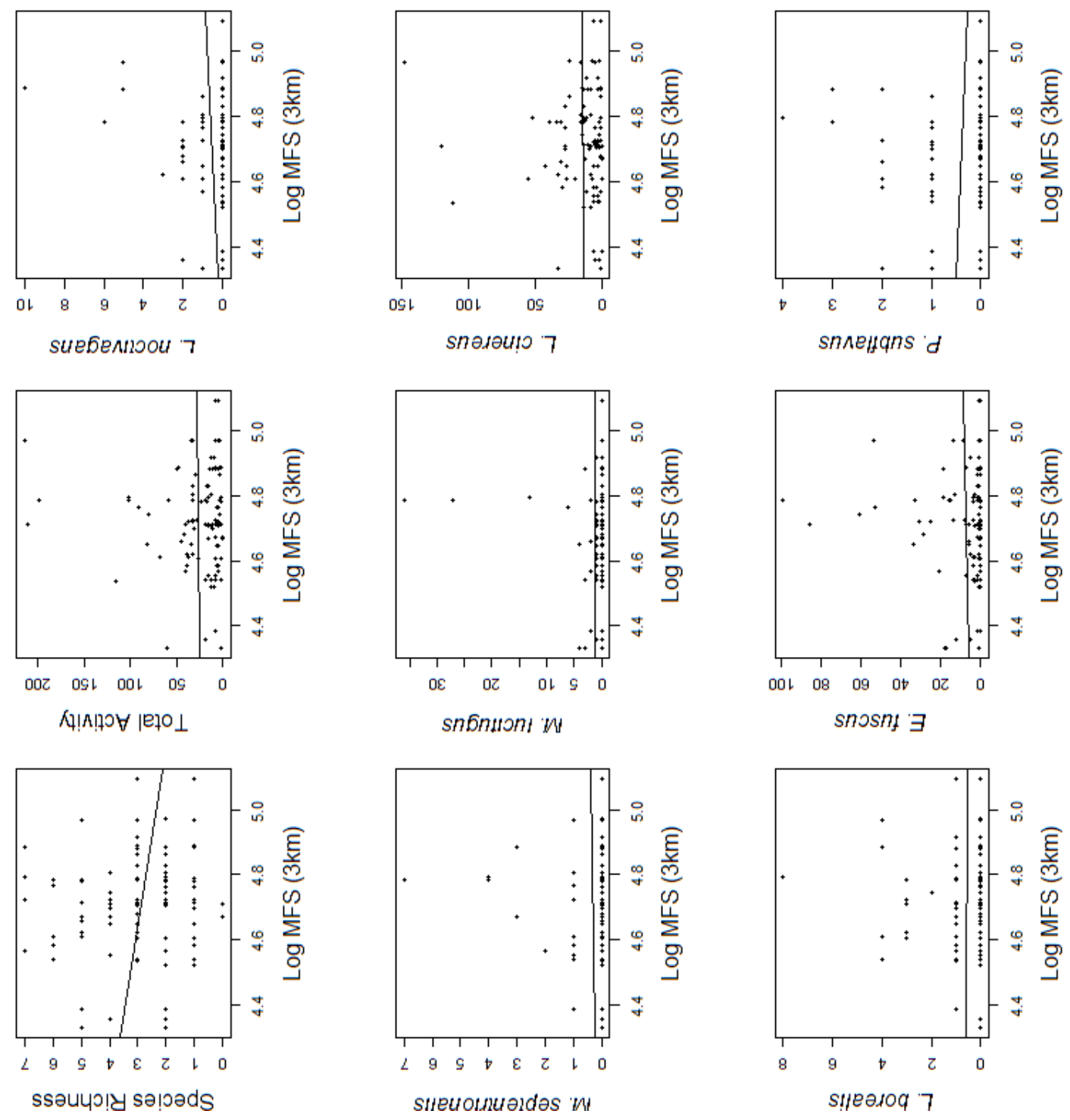


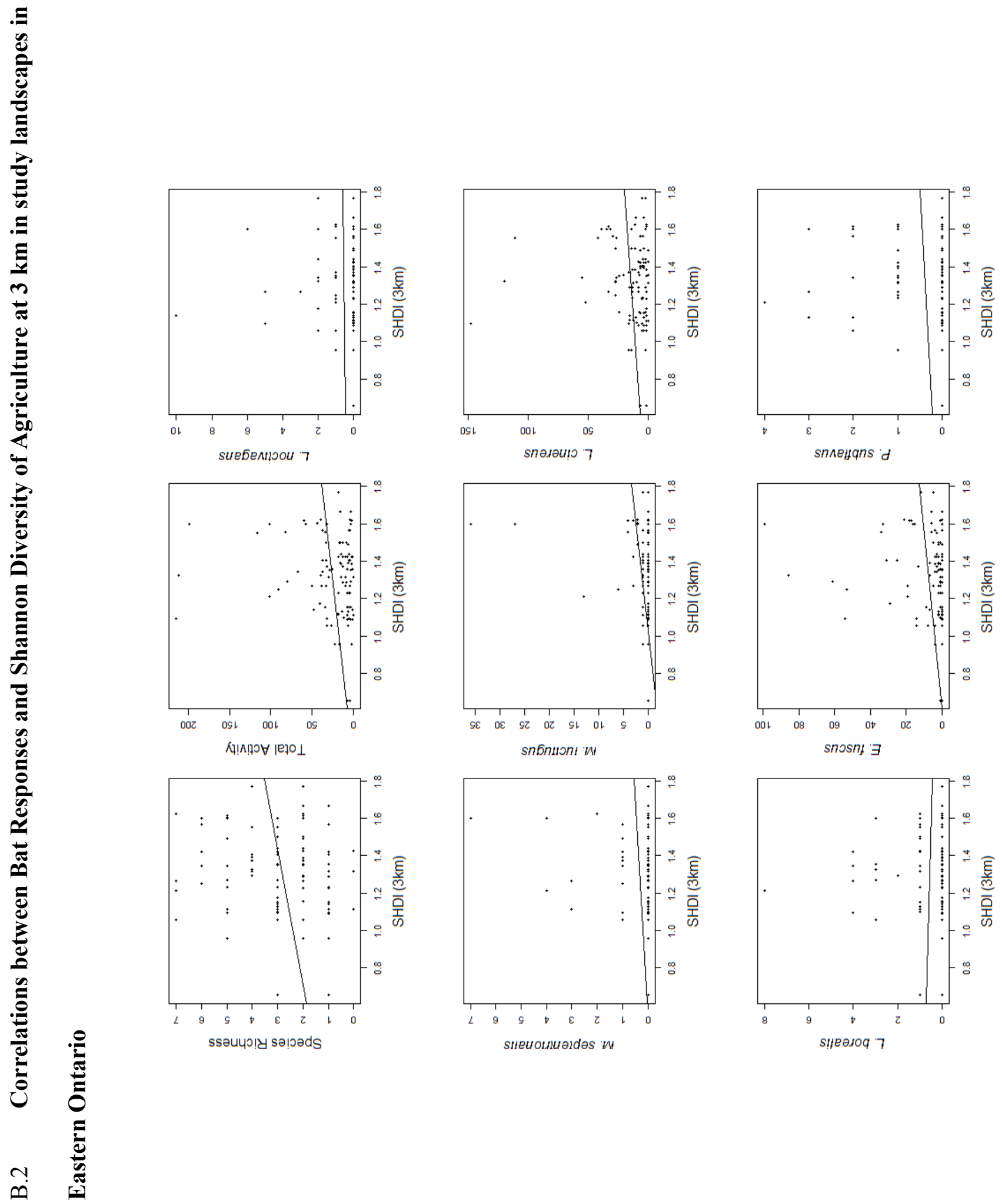



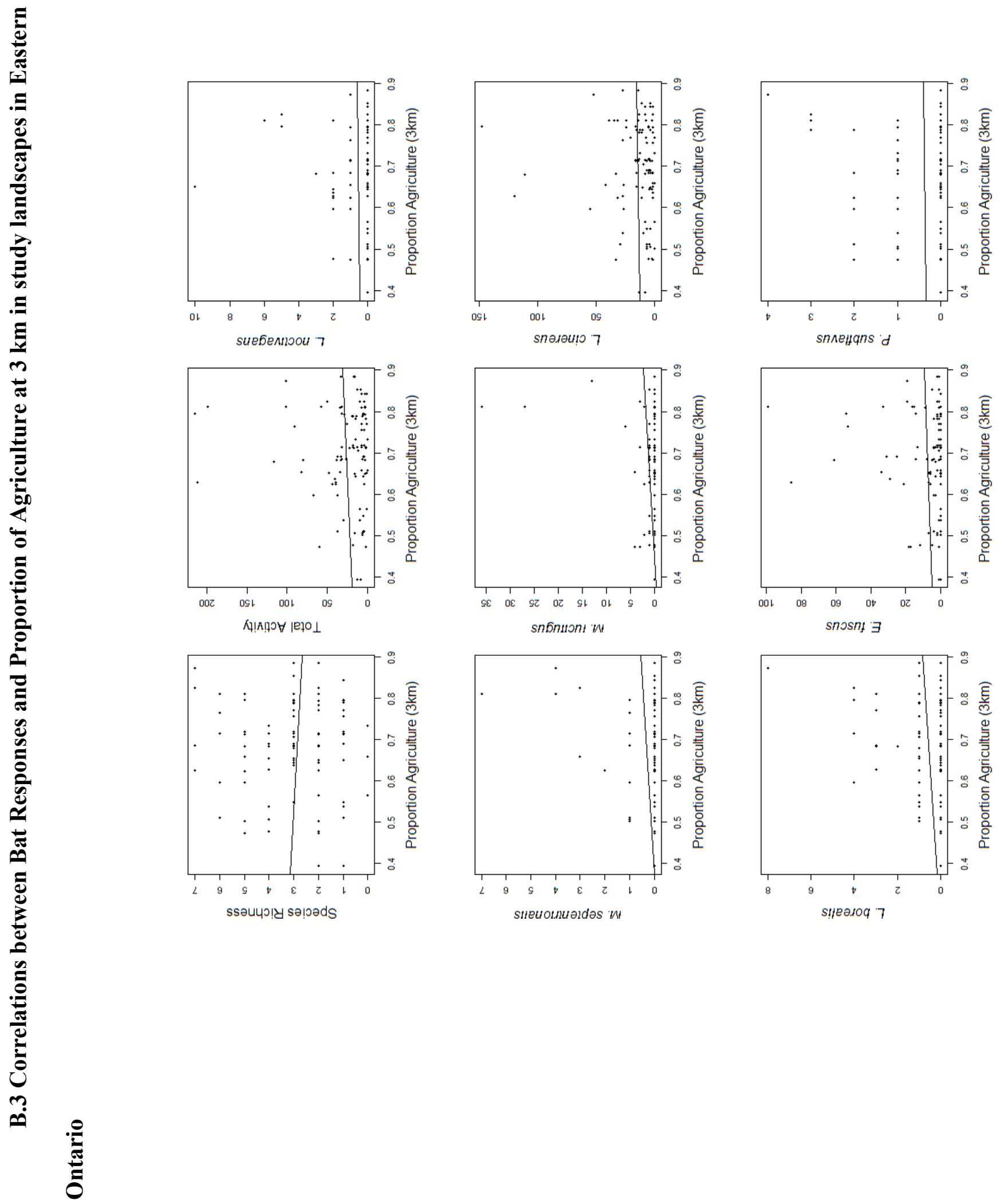

ڤِ 
Appendix C Pearson correlations between percentage forest cover at $3 \mathrm{~km}$ scale and bat response variables recorded in acoustic surveys in agricultural Eastern Ontario study landscapes

\begin{tabular}{lr}
\hline Response & Forest $(3 \mathrm{~km})$ \\
\hline Species Richness & 0.2465 \\
Total Activity & 0.264 \\
L. noctivagans & 0.11 \\
M. septentrionalis & -0.0354 \\
M. lucifugus & 0.1517 \\
L. cinereus & 0.2388 \\
L. borealis & 0.2943 \\
E. fuscus & 0.2081 \\
P. subflavus & 0.2222
\end{tabular}


Appendix D Raw Data - Bat Responses: Species richness, total number of calls, and calls per species recorded at each surveying point on a given night

\begin{tabular}{|c|c|c|c|c|c|c|c|c|c|c|c|c|}
\hline 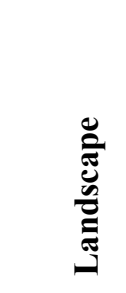 & $\stackrel{\overrightarrow{0}}{0}$ & 䒿 & 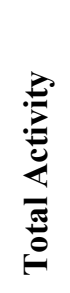 & 悹 & 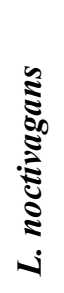 & 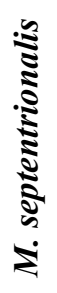 & 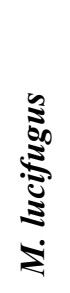 & 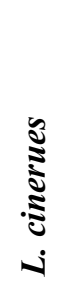 & 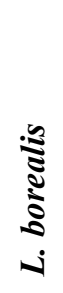 & 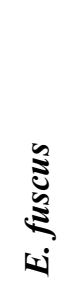 & 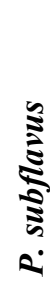 & 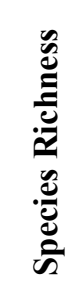 \\
\hline HH11 & HH11.1 & 170 & 6 & 1 & 0 & 0 & 0 & 5 & 0 & 0 & 0 & 1 \\
\hline HH11 & HH11.2 & 170 & 5 & 3 & 1 & 0 & 0 & 1 & 0 & 0 & 0 & 2 \\
\hline HH18 & HH18.1 & 162 & 15 & 0 & 0 & 0 & 0 & 11 & 0 & 4 & 0 & 2 \\
\hline HH18 & HH18.1 & 198 & 15 & 0 & 0 & 0 & 0 & 13 & 0 & 2 & 0 & 2 \\
\hline HН18 & HН18.2 & 198 & 2 & 0 & 0 & 0 & 0 & 1 & 0 & 1 & 0 & 2 \\
\hline HH19 & HH19.1 & 169 & 6 & 1 & 0 & 0 & 0 & 5 & 0 & 0 & 0 & 1 \\
\hline HH19 & HH19.1 & 206 & 4 & 1 & 0 & 0 & 0 & 3 & 0 & 0 & 0 & 1 \\
\hline HH19 & HH19.5 & 169 & 33 & 1 & 0 & 0 & 1 & 6 & 0 & 25 & 0 & 3 \\
\hline HH19 & HH19.5 & 206 & 37 & 0 & 0 & 0 & 1 & 4 & 0 & 31 & 1 & 4 \\
\hline $\mathrm{HH} 2$ & $\mathrm{HH} 2.3$ & 151 & 4 & 2 & 1 & 0 & 0 & 1 & 0 & 0 & 0 & 2 \\
\hline $\mathrm{HH} 2$ & HH2.2 & 151 & 40 & 1 & 1 & 2 & 2 & 11 & 1 & 21 & 1 & 7 \\
\hline HН208 & НH208.4 & 197 & 19 & 7 & 0 & 0 & 0 & 12 & 0 & 0 & 0 & 1 \\
\hline НH208 & HН208.2 & 197 & 18 & 0 & 0 & 0 & 0 & 15 & 1 & 2 & 0 & 3 \\
\hline HH22 & HH22.3 & 156 & 1 & 0 & 0 & 0 & 0 & 0 & 0 & 1 & 0 & 1 \\
\hline HH22 & HH22.3 & 192 & 8 & 0 & 0 & 0 & 0 & 7 & 0 & 1 & 0 & 2 \\
\hline HH22 & HH22.2 & 192 & 26 & 2 & 0 & 0 & 1 & 20 & 3 & 0 & 0 & 3 \\
\hline $\mathrm{HH} 24$ & HH24.1 & 190 & 0 & 0 & 0 & 0 & 0 & 0 & 0 & 0 & 0 & 0 \\
\hline HH24 & HH24.3 & 190 & 0 & 0 & 0 & 0 & 0 & 0 & 0 & 0 & 0 & 0 \\
\hline $\mathrm{HH} 24$ & HH24.2 & 144 & 15 & 0 & 0 & 0 & 1 & 12 & 0 & 1 & 1 & 4 \\
\hline HH26 & HH26.1 & 180 & 2 & 0 & 0 & 0 & 0 & 2 & 0 & 0 & 0 & 1 \\
\hline HH26 & HH26.3 & 149 & 2 & 0 & 0 & 0 & 0 & 2 & 0 & 0 & 0 & 1 \\
\hline HH26 & HH26.3 & 180 & 17 & 0 & 0 & 0 & 1 & 16 & 0 & 0 & 0 & 2 \\
\hline HH26 & HH26.1 & 149 & 23 & 2 & 1 & 0 & 1 & 14 & 0 & 4 & 1 & 5 \\
\hline HH27 & HH27.1 & 163 & 82 & 1 & 1 & 0 & 4 & 42 & 0 & 34 & 0 & 4 \\
\hline $\mathrm{HH} 27$ & HH27.3 & 163 & 34 & 1 & 0 & 0 & 0 & 26 & 1 & 6 & 0 & 3 \\
\hline HH29 & HH29.2 & 211 & 7 & 0 & 0 & 0 & 0 & 3 & 0 & 2 & 2 & 3 \\
\hline HH29 & HH29.4 & 211 & 14 & 0 & 0 & 0 & 0 & 10 & 1 & 0 & 3 & 3 \\
\hline HH3 & HH3.3 & 171 & 10 & 1 & 0 & 0 & 0 & 9 & 0 & 0 & 0 & 1 \\
\hline HH3 & HH3.4 & 171 & 30 & 0 & 0 & 0 & 0 & 27 & 1 & 1 & 1 & 4 \\
\hline HH5 & HH5.2 & 181 & 4 & 1 & 0 & 0 & 0 & 1 & 0 & 2 & 0 & 2 \\
\hline HH5 & HH5.4 & 181 & 10 & 1 & 0 & 0 & 0 & 8 & 0 & 1 & 0 & 2 \\
\hline HH5 & HH5.2 & 158 & 50 & 0 & 5 & 3 & 3 & 13 & 4 & 19 & 3 & 7 \\
\hline
\end{tabular}




\begin{tabular}{|c|c|c|c|c|c|c|c|c|c|c|c|}
\hline HH6 & HH6.1 & 193 & 4 & 0 & 0 & 0 & 0 & 4 & 0 & 0 & 0 \\
\hline HH6 & HH6.2 & 193 & 8 & 0 & 0 & 0 & 0 & 5 & 0 & 2 & 1 \\
\hline HH6 & HH6.1 & 157 & 18 & 1 & 0 & 0 & 1 & 13 & 1 & 1 & 1 \\
\hline HH7 & HH7.1 & 145 & 7 & 0 & 0 & 0 & 0 & 3 & 0 & 4 & 0 \\
\hline HH7 & HH7.3 & 199 & 32 & 18 & 1 & 0 & 0 & 5 & 0 & 8 & 0 \\
\hline HH7 & HH7.1 & 199 & 7 & 3 & 2 & 1 & 0 & 1 & 0 & 0 & 0 \\
\hline HH7 & HH7.3 & 145 & 27 & 2 & 1 & 1 & 1 & 3 & 3 & 14 & 2 \\
\hline HH8 & HH8.1 & 179 & 13 & 2 & 0 & 0 & 0 & 8 & 0 & 3 & 0 \\
\hline HH8 & HH8.4 & 179 & 32 & 1 & 1 & 1 & 0 & 16 & 0 & 13 & 0 \\
\hline HH9 & HH9.4 & 172 & 5 & 0 & 0 & 0 & 0 & 5 & 0 & 0 & 0 \\
\hline HH9 & HН9.3 & 198 & 5 & 0 & 0 & 0 & 0 & 5 & 0 & 0 & 0 \\
\hline HH9 & HH9.3 & 172 & 32 & 1 & 0 & 1 & 0 & 16 & 0 & 14 & 0 \\
\hline HH9 & HH9.4 & 198 & 214 & 2 & 5 & 1 & 0 & 148 & 4 & 54 & 0 \\
\hline HL207 & HL207.2 & 186 & 102 & 1 & 1 & 4 & 13 & 52 & 8 & 19 & 4 \\
\hline HL215 & HL215.2 & 165 & 16 & 0 & 0 & 0 & 0 & 14 & 0 & 2 & 0 \\
\hline HL215 & HL215.3 & 214 & 17 & 2 & 0 & 0 & 0 & 14 & 0 & 1 & 0 \\
\hline HL215 & HL215.2 & 214 & 33 & 3 & 0 & 0 & 0 & 27 & 1 & 2 & 0 \\
\hline HL31 & HL31.4 & 201 & 33 & 17 & 3 & 0 & 0 & 8 & 0 & 5 & 0 \\
\hline HL31 & HL31.5 & 201 & 39 & 0 & 0 & 0 & 1 & 33 & 3 & 1 & 1 \\
\hline HL35 & HL35.4 & 187 & 41 & 9 & 2 & 0 & 0 & 1 & 0 & 29 & 0 \\
\hline HL36 & HL36.4 & 207 & 2 & 0 & 0 & 0 & 0 & 2 & 0 & 0 & 0 \\
\hline HL36 & HL36.1 & 150 & 8 & 2 & 0 & 0 & 1 & 2 & 0 & 3 & 0 \\
\hline HL36 & HL36.4 & 150 & 18 & 4 & 0 & 0 & 0 & 6 & 4 & 4 & 0 \\
\hline HL36 & HL36.3 & 207 & 13 & 2 & 0 & 1 & 3 & 3 & 1 & 2 & 1 \\
\hline HL39 & HL39.1 & 201 & 116 & 1 & 0 & 0 & 0 & 111 & 1 & 3 & 0 \\
\hline HL40 & HL40.2 & 165 & 4 & 0 & 0 & 0 & 0 & 4 & 0 & 0 & 0 \\
\hline HL40 & HL40.7 & 214 & 6 & 0 & 0 & 0 & 0 & 6 & 0 & 0 & 0 \\
\hline HL40 & HL40.1 & 214 & 38 & 0 & 0 & 1 & 1 & 29 & 1 & 4 & 2 \\
\hline HL44 & HL44.4 & 206 & 44 & 1 & 2 & 0 & 2 & 31 & 0 & 6 & 2 \\
\hline HL59 & HL59.4 & 163 & 211 & 2 & 2 & 0 & 1 & 120 & 0 & 86 & 0 \\
\hline HL59 & HL59.1 & 163 & 40 & 2 & 0 & 0 & 1 & 27 & 3 & 7 & 0 \\
\hline LH216 & LH216.4 & 159 & 3 & 1 & 1 & 0 & 0 & 1 & 0 & 0 & 0 \\
\hline LH216 & $\begin{array}{l}\text { LH216.2 } \\
\text { LH68.3mo }\end{array}$ & 159 & 29 & 2 & 0 & 0 & 0 & 24 & 0 & 2 & 1 \\
\hline LH68 & $\mathrm{d}$ & 212 & 3 & 0 & 0 & 0 & 0 & 2 & 0 & 1 & 0 \\
\hline LH68 & LH68.4 & 212 & 80 & 1 & 0 & 0 & 1 & 15 & 2 & 61 & 0 \\
\hline LH72 & LH72.6 & 194 & 16 & 1 & 0 & 1 & 1 & 6 & 0 & 7 & 0 \\
\hline LH72 & LH72.8 & 194 & 7 & 0 & 0 & 1 & 0 & 3 & 0 & 2 & 1 \\
\hline LH73 & LH73.2 & 149 & 34 & 1 & 0 & 0 & 0 & 24 & 0 & 9 & 0 \\
\hline LH73 & LH73.2 & 200 & 3 & 0 & 0 & 0 & 0 & 2 & 0 & 1 & 0 \\
\hline LH73 & LH73.3 & 200 & 8 & 0 & 0 & 0 & 0 & 7 & 0 & 1 & 0 \\
\hline LH74 & LH74.4 & 200 & 91 & 2 & 1 & 1 & 6 & 27 & 0 & 53 & 1 \\
\hline LH82 & LH82.2 & 173 & 3 & 0 & 0 & 0 & 0 & 3 & 0 & 0 & 0 \\
\hline
\end{tabular}




\begin{tabular}{|c|c|c|c|c|c|c|c|c|c|c|c|}
\hline LH82 & LH82.4 & 173 & 16 & 0 & 0 & 0 & 0 & 10 & 0 & 6 & 0 \\
\hline LH87 & LH87.1 & 185 & 9 & 0 & 0 & 0 & 1 & 3 & 0 & 5 & 0 \\
\hline LH87 & LH87.3 & 185 & 13 & 0 & 0 & 0 & 0 & 11 & 1 & 1 & 0 \\
\hline LL102 & LL102.2 & 190 & 13 & 0 & 0 & 0 & 0 & 13 & 0 & 0 & 0 \\
\hline LL102 & LL102.4 & 190 & 9 & 0 & 0 & 0 & 0 & 8 & 0 & 1 & 0 \\
\hline LL105 & LL105.2 & 156 & 6 & 0 & 0 & 0 & 0 & 6 & 0 & 0 & 0 \\
\hline LL105 & LL105.1 & 156 & 5 & 0 & 0 & 0 & 1 & 3 & 1 & 0 & 0 \\
\hline LL118 & LL118.2 & 181 & 37 & 1 & 2 & 0 & 0 & 26 & 4 & 3 & 1 \\
\hline LL118 & LL118.3 & 181 & 67 & 3 & 1 & 1 & 0 & 55 & 1 & 4 & 2 \\
\hline LL20 & LL20.1 & 180 & 3 & 0 & 0 & 0 & 0 & 3 & 0 & 0 & 0 \\
\hline LL20 & LL20.1 & 208 & 8 & 0 & 0 & 0 & 0 & 8 & 0 & 0 & 0 \\
\hline LL20 & LL20.3 & 208 & 1 & 0 & 0 & 0 & 0 & 1 & 0 & 0 & 0 \\
\hline LL202 & LL202.1 & 194 & 2 & 0 & 0 & 0 & 0 & 1 & 0 & 1 & 0 \\
\hline LL202 & LL202.2 & 204 & 60 & 5 & 1 & 0 & 3 & 33 & 0 & 17 & 1 \\
\hline LL202 & LL202.1 & 204 & 60 & 2 & 1 & 0 & 4 & 33 & 0 & 18 & 2 \\
\hline LL203 & LL203.2 & 158 & 15 & 6 & 2 & 0 & 0 & 4 & 0 & 3 & 0 \\
\hline LL203 & LL203.5alt & 158 & 5 & 2 & 0 & 0 & 1 & 2 & 0 & 0 & 0 \\
\hline LL204 & LL204.4 & 145 & 1 & 0 & 0 & 0 & 0 & 1 & 0 & 0 & 0 \\
\hline LL204 & LL204.4 & 186 & 48 & 16 & 10 & 0 & 0 & 15 & 0 & 7 & 0 \\
\hline LL211 & LL211.6 & 172 & 18 & 1 & 0 & 0 & 0 & 5 & 0 & 12 & 0 \\
\hline LL211 & LL211.3 & 172 & 18 & 8 & 2 & 0 & 1 & 2 & 0 & 5 & 0 \\
\hline LL217 & LL217.2 & 191 & 32 & 1 & 2 & 0 & 0 & 14 & 0 & 15 & 0 \\
\hline LL217 & LL217.3 & 159 & 101 & 5 & 0 & 4 & 27 & 31 & 1 & 33 & 0 \\
\hline LL217 & LL217.2 & 178 & 58 & 1 & 2 & 0 & 2 & 34 & 3 & 16 & 0 \\
\hline LL217 & LL217.3 & 191 & 3 & 0 & 0 & 0 & 0 & 2 & 0 & 0 & 1 \\
\hline LL217 & LL217.3 & 178 & 199 & 9 & 6 & 7 & 36 & 39 & 0 & 99 & 3 \\
\hline LL75 & LL75.2 & 160 & 7 & 0 & 0 & 0 & 0 & 6 & 1 & 0 & 0 \\
\hline LL75 & LL75.4 & 160 & 7 & 0 & 0 & 1 & 2 & 0 & 1 & 2 & 1 \\
\hline LL79 & LL79.4 & 166 & 0 & 0 & 0 & 0 & 0 & 0 & 0 & 0 & 0 \\
\hline LL79 & LL79.1 & 166 & 8 & 0 & 0 & 3 & 1 & 1 & 1 & 2 & 0 \\
\hline LL80 & LL80.2 & 157 & 4 & 3 & 0 & 0 & 0 & 1 & 0 & 0 & 0 \\
\hline LL80 & LL80.4 & 157 & 8 & 0 & 0 & 0 & 0 & 6 & 1 & 1 & 0 \\
\hline LL91 & LL91.6 & 169 & 12 & 1 & 0 & 0 & 0 & 9 & 1 & 1 & 0 \\
\hline LL93 & LL93.1 & 162 & 1 & 1 & 0 & 0 & 0 & 0 & 0 & 0 & 0 \\
\hline LL93 & LL93.4 & 162 & 10 & 1 & 0 & 0 & 0 & 8 & 1 & 0 & 0 \\
\hline
\end{tabular}




\section{Appendix E Raw Data - Insect totals and potential confounding variables at}

\section{surveying points on a given night}

\begin{tabular}{|c|c|c|c|c|c|c|c|c|c|c|c|c|c|c|}
\hline 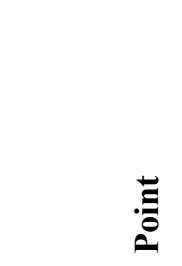 & 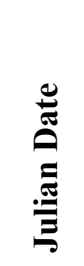 & 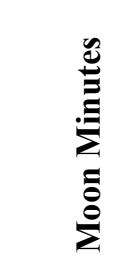 & 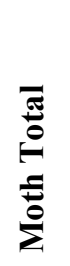 & 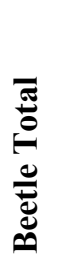 & 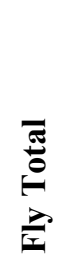 & 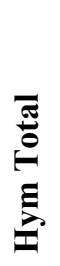 & 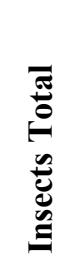 & 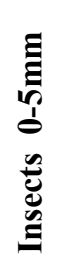 & 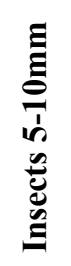 & 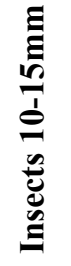 & 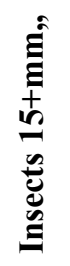 & 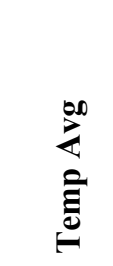 & 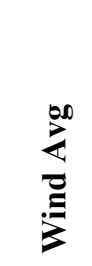 & 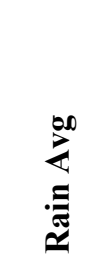 \\
\hline HH11.1 & 170 & 0 & 0 & 3 & 9 & 0 & 14 & 5 & 0 & 0 & 0 & 16.24 & 1.03 & 4.37 \\
\hline HH11.2 & 170 & 0 & 3 & 0 & 10 & 0 & 17 & 3 & 1 & 3 & 0 & 16.24 & 1.03 & 4.37 \\
\hline HH18.1 & 162 & 0 & 0 & 6 & 23 & 0 & 59 & 6 & 1 & 0 & 0 & & & \\
\hline HH18.1 & 198 & 0 & 0 & 10 & 11 & 0 & 22 & 7 & 3 & 0 & 1 & 24.71 & 4.91 & 0.00 \\
\hline HH18.2 & 198 & 0 & 0 & 5 & 16 & 2 & 24 & 6 & 0 & 1 & 1 & 24.71 & 4.91 & 0.00 \\
\hline HH19.1 & 169 & 0 & 0 & 1 & 35 & 0 & 37 & 0 & 0 & 1 & 0 & 21.87 & 6.77 & 0.00 \\
\hline HH19.1 & 206 & 4819.1 & 0 & 8 & 84 & 3 & 97 & 10 & 1 & 2 & 0 & 18.90 & 0.00 & 5.14 \\
\hline HH19.5 & 169 & 0 & 0 & 6 & 28 & 4 & 42 & 10 & 3 & 0 & 1 & 21.87 & 4.53 & 0.00 \\
\hline HH19.5 & 206 & 4819.1 & 2 & 4 & 29 & 0 & 37 & 3 & 3 & 1 & 0 & 18.90 & 0.00 & 5.14 \\
\hline HH2.3 & 151 & 13284 & & & & & & & & & & 18.90 & 0.00 & 5.14 \\
\hline $\mathrm{HH} 2.2$ & 151 & 13284 & & & & & & & & & & 18.90 & 0.00 & 5.14 \\
\hline НH208.4 & 197 & 0 & & & & & & & & & & 21.49 & 0.00 & 6.30 \\
\hline НH208.2 & 197 & $\begin{array}{r}0 \\
15184 .\end{array}$ & 1 & 9 & 86 & 3 & 101 & 13 & 2 & 0 & 0 & 21.49 & 0.00 & 6.30 \\
\hline $\mathrm{HH} 22.3$ & 156 & 8 & 0 & 1 & 6 & 0 & 7 & 1 & 0 & 0 & 0 & & & \\
\hline HH22.3 & 192 & 0 & 0 & 1 & 2 & 1 & 5 & 3 & 0 & 0 & 0 & 21.49 & 0.00 & 6.30 \\
\hline HH22.2 & 192 & 0 & 2 & 9 & 12 & 0 & 31 & 16 & 1 & 1 & 0 & 21.49 & 0.00 & 6.30 \\
\hline HH24.1 & 190 & 2046.6 & 0 & 5 & 35 & 7 & 49 & 14 & 0 & 0 & 0 & 27.81 & 6.94 & 0.00 \\
\hline $\mathrm{HH} 24.3$ & 190 & 2046.6 & 0 & 6 & 22 & 2 & 34 & 7 & 5 & 0 & 0 & 27.81 & 6.94 & 0.00 \\
\hline HH24.2 & 144 & 994 & 1 & 8 & 12 & 2 & 30 & 15 & 2 & 0 & 1 & 23.31 & 0.00 & 0.00 \\
\hline НH26.1 & 180 & 12762 & 0 & 12 & 20 & 9 & 44 & 23 & 1 & 0 & 0 & 21.64 & 0.00 & 0.00 \\
\hline HH26.3 & 149 & 12762 & 0 & 1 & 15 & 3 & 27 & 8 & 0 & 1 & 0 & 21.64 & 0.00 & 0.00 \\
\hline HH26.3 & 180 & 12762 & 0 & 40 & 22 & 1 & 66 & 40 & 2 & 1 & 1 & 20.68 & 0.00 & 0.00 \\
\hline HH26.1 & 149 & 9252 & 0 & 2 & 22 & 2 & 30 & 8 & 0 & 0 & 0 & 23.31 & 0.00 & 0.00 \\
\hline HH27.1 & 163 & 0 & 0 & 10 & 28 & 3 & 59 & 29 & 2 & 0 & 0 & 22.70 & 0.51 & 0.00 \\
\hline HН27.3 & 163 & 0 & 0 & 4 & 35 & 6 & 81 & 39 & 2 & 0 & 0 & 22.70 & 0.51 & 0.00 \\
\hline HH29.2 & 211 & 15858 & 0 & 7 & 11 & 0 & 22 & 9 & 1 & 1 & 0 & 21.81 & 1.19 & 0.00 \\
\hline HH29.4 & 211 & 15858 & 0 & 2 & 4 & 3 & 11 & 6 & 0 & 1 & 0 & 21.81 & 1.19 & 0.00 \\
\hline HH3.3 & 171 & 0 & & & & & & & & & & 15.87 & 0.31 & 0.00 \\
\hline HН3.4 & 171 & 0 & 1 & 1 & 3 & 1 & 9 & 5 & 1 & 0 & 0 & 15.87 & 0.31 & 0.00 \\
\hline
\end{tabular}




\begin{tabular}{|c|c|c|c|c|c|c|c|c|c|c|c|c|c|c|}
\hline HH5.2 & 181 & 14634 & 0 & 2 & 34 & 0 & 42 & 8 & 0 & 0 & 0 & 17.77 & 0.00 & 0.00 \\
\hline HH5.4 & 181 & 14634 & 1 & 3 & 2 & 0 & 8 & 4 & 2 & 0 & 0 & 17.77 & 0.00 & 0.00 \\
\hline HH5.2 & 158 & 4950.4 & 0 & 0 & 9 & 0 & 10 & 0 & 0 & 1 & 0 & & & \\
\hline HH6.1 & 193 & 0 & 0 & 0 & 12 & 0 & 13 & 1 & 0 & 0 & 0 & 11.87 & 0.00 & 0.00 \\
\hline HH6.2 & 193 & 0 & 0 & 4 & 27 & 0 & 33 & 6 & 0 & 0 & 0 & 11.87 & 0.00 & 0.00 \\
\hline HH6.1 & 157 & 9612.7 & 3 & 5 & 31 & 0 & 39 & 4 & 2 & 2 & 0 & 16.14 & 0.87 & 0.00 \\
\hline НH7.1 & 145 & 2270.4 & 0 & 1 & 33 & 6 & 42 & 9 & 0 & 0 & 0 & 15.24 & 0.16 & 0.00 \\
\hline HН7.3 & 199 & 0 & & & & & & & & & & & & \\
\hline HH7.1 & 199 & 0 & & & & & & & & & & & & \\
\hline HH7.3 & 145 & 2270.4 & 0 & 0 & 0 & 0 & 0 & 0 & 0 & 0 & 0 & 15.24 & 0.16 & 0.00 \\
\hline HH8.1 & 179 & 10728 & 2 & 1 & 72 & 0 & 75 & 2 & 0 & 2 & 0 & 15.84 & 5.59 & 0.00 \\
\hline HH8.4 & 179 & 10728 & 4 & 0 & 10 & 1 & 15 & 3 & 0 & 2 & 0 & 15.84 & 5.59 & 0.00 \\
\hline HH9.4 & 172 & 63.7 & 3 & 8 & 12 & 1 & 24 & 3 & 8 & 1 & 0 & 24.37 & 8.12 & 0.00 \\
\hline HН9.3 & 198 & 0 & 1 & 3 & 13 & 1 & 18 & 1 & 4 & 1 & 0 & 22.14 & 3.33 & 0.00 \\
\hline HH9.3 & 172 & 63.7 & 4 & 0 & 10 & 1 & 15 & 3 & 0 & 2 & 0 & 22.14 & 3.33 & 0.00 \\
\hline HH9.4 & 198 & $\begin{array}{r}0 \\
14043 .\end{array}$ & 2 & 4 & 11 & 1 & 18 & 2 & 4 & 1 & 1 & 24.37 & 8.12 & 0.00 \\
\hline HL207.2 & 186 & 6 & 0 & 3 & 7 & 2 & 15 & 7 & 1 & 0 & 0 & 17.37 & 0.00 & 0.86 \\
\hline HL215.2 & 165 & 17766 & 0 & 1 & 9 & 0 & 12 & 1 & 1 & 1 & 0 & 18.09 & 0.36 & 0.00 \\
\hline HL215.3 & 214 & 17766 & 6 & 2 & 8 & 0 & 16 & 4 & 2 & 0 & 4 & 15.77 & 0.00 & 0.00 \\
\hline HL215.2 & 214 & 0 & 2 & 4 & 7 & 0 & 14 & 5 & 1 & 1 & 0 & 15.77 & 0.00 & 0.00 \\
\hline HL31.4 & 201 & 1.5 & & & & & & & & & & 19.81 & 0.63 & 1.93 \\
\hline HL31.5 & 201 & $\begin{array}{r}1.5 \\
10368 .\end{array}$ & 5 & 1 & 4 & 1 & 11 & 3 & 6 & 2 & 1 & 20.20 & 0.00 & 0.00 \\
\hline HL35.4 & 187 & 3 & & & & & & & & & & 19.81 & 0.63 & 1.93 \\
\hline HL36.4 & 207 & 8118 & 2 & 1 & 14 & 3 & 20 & 2 & 4 & 2 & 0 & 10.17 & 0.16 & 0.00 \\
\hline HL36.1 & 150 & 11304 & 6 & 2 & 5 & 0 & 13 & 4 & 2 & 2 & 1 & 20.20 & 0.00 & 0.00 \\
\hline HL36.4 & 150 & 11304 & 1 & 7 & 24 & 0 & 32 & 1 & 16 & 0 & 0 & 18.70 & 0.00 & 0.00 \\
\hline HL36.3 & 207 & 8118 & 1 & 0 & 1 & 0 & 2 & 1 & 0 & 0 & 0 & 13.79 & 0.00 & 0.00 \\
\hline HL39.1 & 201 & 1.5 & 7 & 3 & 20 & 3 & 33 & 7 & 14 & 0 & 0 & 18.70 & 0.00 & 0.00 \\
\hline HL40.2 & 165 & 0 & 1 & 5 & 7 & 0 & 13 & 1 & 6 & 1 & 0 & 15.10 & 0.00 & 0.00 \\
\hline HL40.7 & 214 & 17766 & 0 & 3 & 3 & 0 & 11 & 6 & 2 & 0 & 0 & 25.06 & 5.63 & 0.00 \\
\hline HL40.1 & 214 & 17766 & 5 & 1 & 4 & $\begin{array}{l}0 \\
1\end{array}$ & 10 & 4 & 1 & 0 & 1 & 25.06 & 5.63 & 0.00 \\
\hline HL44.4 & 206 & 4819.1 & 0 & 4 & 20 & 5 & 46 & 23 & 3 & 0 & 0 & 20.37 & 0.00 & 10.67 \\
\hline HL59.4 & 163 & 0 & 0 & 11 & 7 & 5 & 30 & 22 & 1 & 0 & 0 & 20.37 & 0.00 & 10.67 \\
\hline HL59.1 & 163 & 0 & 1 & 48 & 15 & 0 & 67 & 12 & 40 & 0 & 0 & 20.37 & 0.00 & 10.67 \\
\hline LH216.4 & 159 & 0 & & & & & & & & & & 22.27 & 4.04 & 0.00 \\
\hline $\begin{array}{l}\text { LH216.2 } \\
\text { LH68.3mo }\end{array}$ & 159 & 1419.2 & 0 & 5 & 5 & 2 & 18 & 12 & 1 & 0 & 0 & 22.27 & 4.04 & 0.00 \\
\hline $\mathrm{d}$ & 212 & 17046 & 0 & 0 & 0 & 0 & 0 & 0 & 0 & 0 & 0 & 15.37 & 0.36 & 0.00 \\
\hline LH68.4 & 212 & 17046 & 1 & 1 & 10 & 0 & 13 & 2 & 1 & 0 & 0 & 15.37 & 0.36 & 0.00 \\
\hline LH72.6 & 194 & 0 & 2 & 2 & 6 & 0 & 12 & 3 & 3 & 0 & 0 & 15.39 & 1.07 & 5.36 \\
\hline LH72.8 & 194 & 0 & 0 & 1 & 2 & 0 & 6 & 0 & 0 & 0 & 1 & 15.39 & 1.07 & 5.36 \\
\hline LH73.2 & 149 & 9252 & 0 & 0 & 3 & 0 & 6 & 0 & 0 & 0 & 0 & 15.81 & 0.36 & 6.17 \\
\hline
\end{tabular}




\begin{tabular}{|c|c|c|c|c|c|c|c|c|c|c|c|c|c|c|}
\hline LH73.2 & 200 & 0 & 0 & 0 & 9 & 0 & 10 & 1 & 0 & 0 & 0 & 15.00 & 0.67 & 0.00 \\
\hline LH73.3 & 200 & 0 & 0 & 1 & 10 & 0 & 12 & 1 & 0 & 0 & 1 & 15.00 & 0.67 & 0.00 \\
\hline LH74.4 & 200 & 0 & 0 & 2 & 0 & 0 & 3 & 2 & 0 & 0 & 1 & 15.33 & 3.03 & 0.00 \\
\hline LH82.2 & 173 & 386.4 & 0 & 0 & 2 & 0 & 3 & 1 & 0 & 0 & 0 & & & \\
\hline LH82.4 & 173 & 386.4 & 0 & 11 & 15 & 0 & 27 & 7 & 2 & 2 & 3 & & & \\
\hline LH87.1 & 185 & 17892 & 0 & 16 & 89 & 0 & 105 & 13 & 2 & 1 & 0 & 20.56 & 4.71 & 3.13 \\
\hline LH87.3 & 185 & 17892 & 1 & 3 & 6 & 0 & 27 & 18 & 1 & 0 & 2 & 20.56 & 4.71 & 3.13 \\
\hline LL102.2 & 190 & 2046.6 & 2 & 4 & 6 & 0 & 13 & 3 & 3 & 1 & 0 & 20.97 & 4.00 & 0.00 \\
\hline LL102.4 & 190 & $\begin{array}{l}2046.6 \\
15184 .\end{array}$ & 0 & 5 & 6 & 0 & 11 & 3 & 1 & 0 & 1 & 20.97 & $\begin{array}{l}4.00 \\
13.1\end{array}$ & 0.00 \\
\hline LL105.2 & 156 & $\begin{array}{r}8 \\
15184 .\end{array}$ & 0 & 3 & 5 & 2 & 11 & 5 & 1 & 0 & 0 & 10.22 & $\begin{array}{r}5 \\
13.1\end{array}$ & 0.00 \\
\hline LL105.1 & 156 & 8 & 0 & 7 & 14 & 0 & 22 & 7 & 0 & 1 & 0 & 10.22 & 5 & 0.00 \\
\hline LL118.2 & 181 & 14634 & 0 & 2 & 3 & 0 & 8 & 4 & 0 & 0 & 1 & 12.84 & 0.00 & 13.11 \\
\hline LL118.3 & 181 & 14634 & 0 & 0 & 13 & 2 & 20 & 6 & 0 & 1 & 0 & 12.84 & 0.00 & 13.11 \\
\hline LL20.1 & 180 & 12762 & 0 & 0 & 5 & 0 & 5 & 0 & 0 & 0 & 0 & 23.16 & 6.36 & 3.84 \\
\hline LL20.1 & 208 & 10260 & 0 & 0 & 3 & 0 & 4 & 1 & 0 & 0 & 0 & 12.20 & 0.16 & 0.00 \\
\hline LL20.3 & 208 & 10260 & 0 & 8 & 18 & 0 & 26 & 8 & 0 & 0 & 0 & 12.20 & 0.16 & 0.00 \\
\hline LL202.1 & 194 & 0 & 1 & 7 & 6 & 0 & 15 & 7 & 2 & 0 & 0 & 21.26 & 2.94 & 0.00 \\
\hline LL202.2 & 204 & 1261.5 & 3 & 1 & 4 & 0 & 10 & 3 & 2 & 1 & 0 & 23.16 & 6.36 & 3.84 \\
\hline LL202.1 & 204 & 1261.5 & 3 & 3 & 16 & 1 & 28 & 7 & 3 & 0 & 2 & 23.16 & 6.36 & 3.84 \\
\hline LL203.2 & 158 & 4950.4 & 0 & 1 & 13 & 0 & 15 & 2 & 0 & 0 & 0 & 23.43 & 3.53 & 0.00 \\
\hline LL203.5alt & 158 & $\begin{array}{r}2856 \\
14043 .\end{array}$ & 1 & 2 & 7 & 0 & 11 & 3 & 0 & 0 & 1 & 23.43 & 3.53 & 0.00 \\
\hline LL204.4 & 145 & 6 & 0 & 5 & 4 & 0 & 9 & 4 & 0 & 1 & 0 & 16.44 & 0.16 & 0.00 \\
\hline LL204.4 & 186 & 2270.4 & & & & & & & & & & & & \\
\hline LL211.6 & 172 & 63.7 & 0 & 2 & 10 & 0 & 16 & 4 & 0 & 1 & 1 & 22.96 & 6.79 & 0.00 \\
\hline LL211.3 & 172 & 63.7 & 0 & 2 & 35 & 0 & 40 & 0 & 2 & 3 & 0 & 22.96 & 6.79 & 0.00 \\
\hline LL217.2 & 191 & 8622 & 2 & 2 & 14 & 6 & 32 & 16 & 1 & 0 & 1 & 22.91 & 1.14 & 0.47 \\
\hline LL217.3 & 159 & 1419.2 & 2 & 24 & 9 & 1 & 38 & 7 & 20 & 0 & 2 & 12.00 & 0.99 & 0.00 \\
\hline LL217.2 & 178 & 132.6 & 0 & 4 & 11 & 3 & 31 & 18 & 2 & 0 & 0 & 26.08 & 2.27 & 33.51 \\
\hline LL217.3 & 191 & 8622 & 0 & 0 & 2 & 0 & 3 & 1 & 0 & 0 & 0 & 22.91 & 1.14 & 0.47 \\
\hline LL217.3 & 178 & 132.6 & 1 & 6 & 13 & 1 & 23 & 4 & 6 & 0 & 0 & 26.08 & 2.27 & 33.51 \\
\hline LL75.2 & 160 & 0 & 0 & 4 & 6 & 2 & 19 & 10 & 3 & 0 & 0 & 21.26 & 0.36 & 0.00 \\
\hline LL75.4 & 160 & 0 & 1 & 5 & 4 & 1 & 16 & 9 & 4 & 2 & 0 & 21.26 & 0.36 & 0.00 \\
\hline LL79.4 & 166 & 0 & 0 & 4 & 22 & 0 & 52 & 4 & 0 & 0 & 0 & 15.00 & 5.96 & 1.63 \\
\hline LL79.1 & 166 & 0 & 0 & 4 & 8 & 3 & 32 & 6 & 3 & 0 & 0 & 15.00 & 5.96 & 1.63 \\
\hline LL80.2 & 157 & 9612.7 & 0 & 0 & 17 & $\begin{array}{l}0 \\
1\end{array}$ & 17 & 0 & 0 & 0 & 0 & 12.30 & 0.51 & 0.00 \\
\hline LL80.4 & 157 & 9612.7 & 0 & 2 & 33 & 7 & 82 & 48 & 1 & 0 & 0 & 12.30 & 0.51 & 0.00 \\
\hline LL91.6 & 169 & 0 & 0 & 5 & 20 & 6 & 67 & 15 & 1 & 0 & 0 & 15.06 & & 13.93 \\
\hline LL93.1 & 162 & 0 & & & & 1 & & & & & & 12.30 & 0.51 & 0.00 \\
\hline LL93.4 & 162 & 0 & 0 & 0 & 28 & 2 & 80 & 52 & 0 & 0 & 0 & 12.30 & 0.51 & 0.00 \\
\hline
\end{tabular}




\section{Appendix F Raw Data - Study landscapes: Location, Log of mean field size, proportion agricultural cover, Shannon Diversity of agriculture, and proportion} forest cover

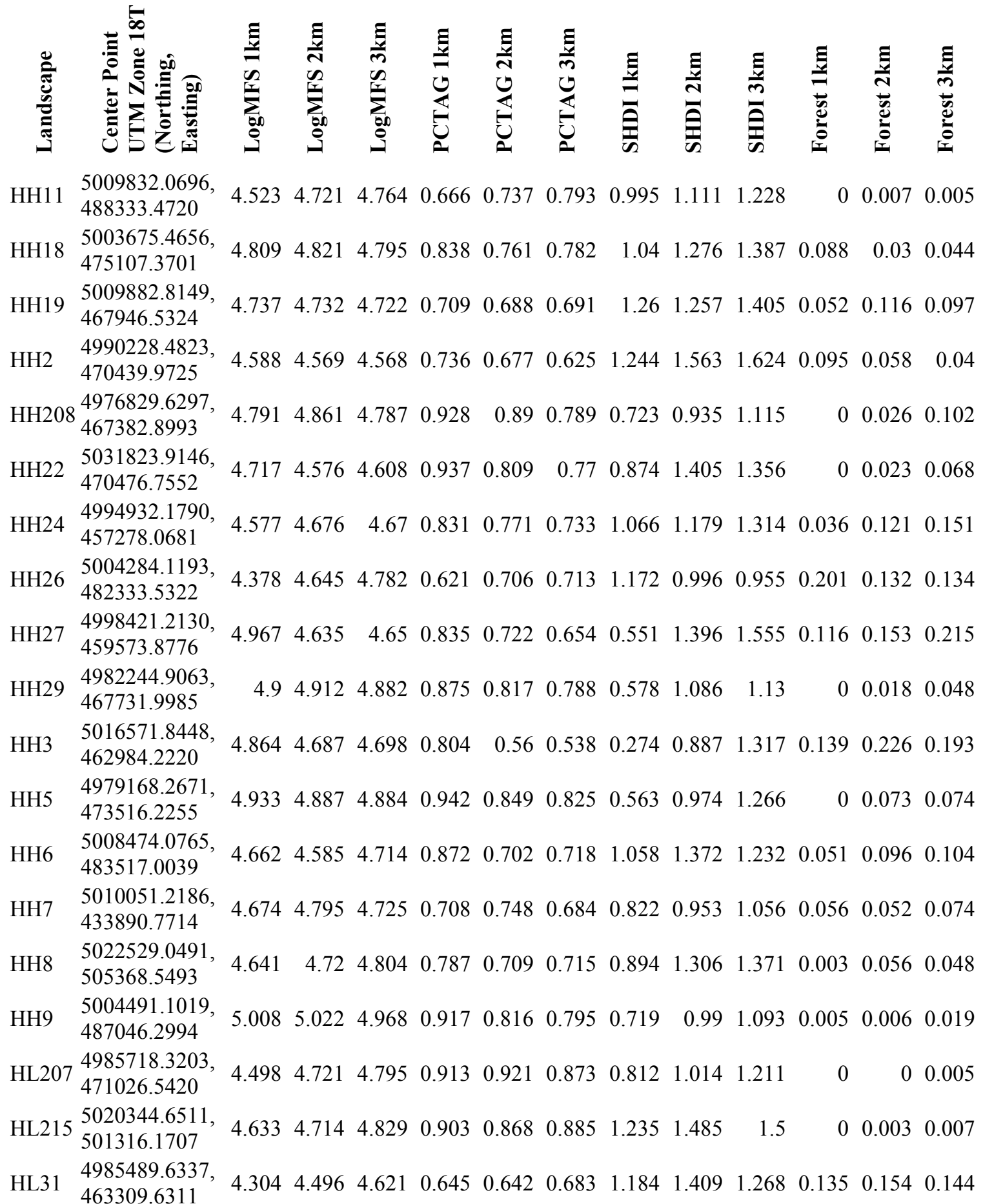




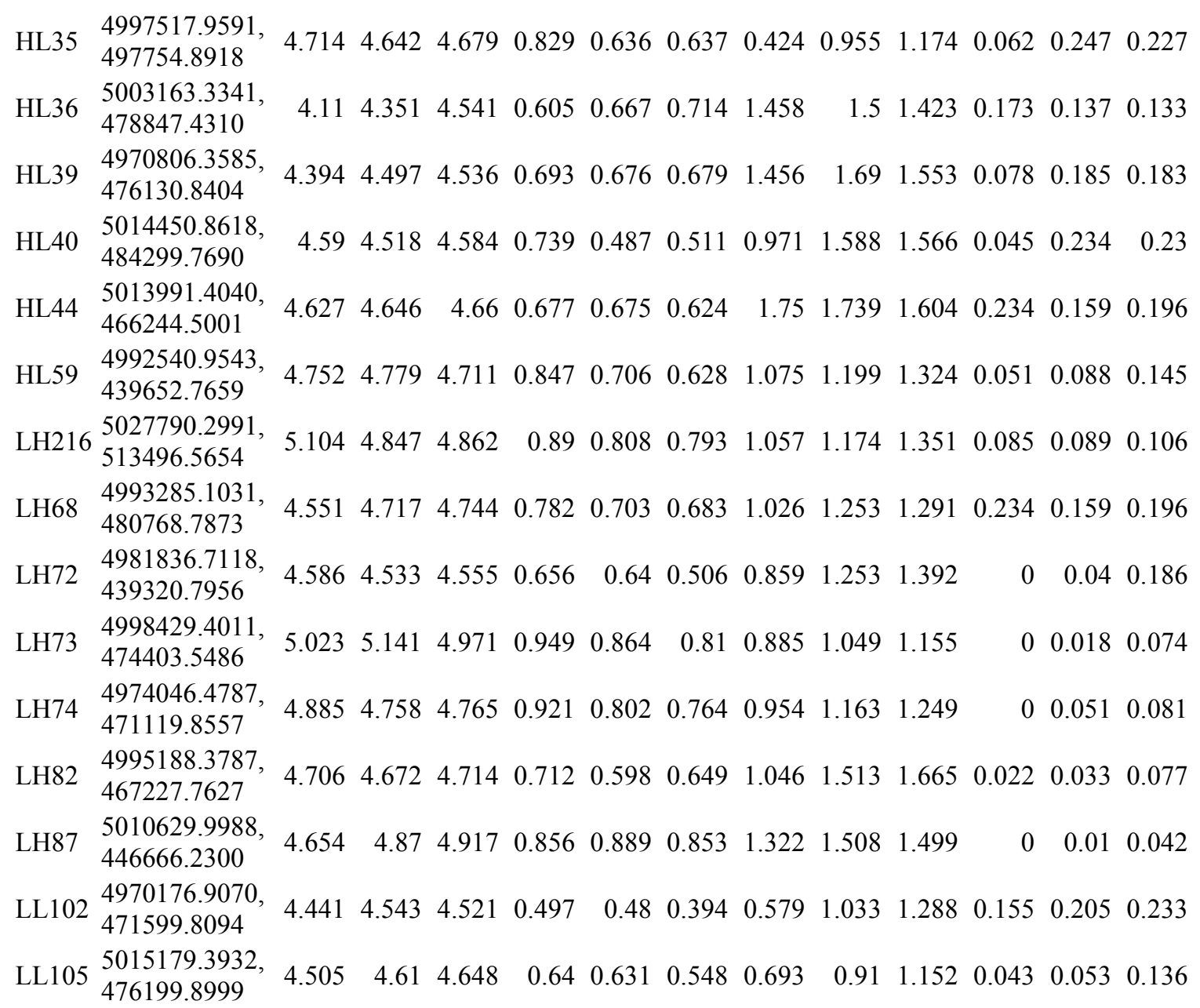




\section{References}

Agosta, S. J., D. Morton, and K. M. Kuhn. 2003. Feeding ecology of the bat Eptesicus fuscus: "preferred" prey abundance as one factor influencing prey selection and diet breadth. Journal of Zoology 260:169-177.

Anthony, E., and T. Kunz. 1977. Feeding strategies of the little brown bat, Myotis lucifugus, in southern New Hampshire. Ecology 58:775-786.

Attademo, A. M., P. M. Peltzer, and R. C. Lajmanovich. 2005. Amphibians occurring in soybean and implications for biological control in Argentina. Agriculture, Ecosystems and Environment 106:389-394.

Aviron, S., F. Burel, J. Baudry, and N. Schermann. 2005. Carabid assemblages in agricultural landscapes: impacts of habitat features, landscape context at different spatial scales and farming intensity. Agriculture, Ecosystems and Environment 108:205-217.

Barclay, R. 1985. Long-versus short-range foraging strategies of Hoary (Lasiurus cinereus) and Silver-haired (Lasionycteris noctivagans) Bats and the consequences for prey selection. Canadian Journal of Zoology 63:2507-2515.

Bennett, A. F., J. Q. Radford, and A. Haslem. 2006. Properties of land mosaics: Implications for nature conservation in agricultural environments. Biological Conservation 133:250-264.

Benton, T. G., J. A. Vickery, and J. D. Wilson. 2003. Farmland biodiversity: is habitat heterogeneity the key? Trends in Ecology \& Evolution 18:182-188.

Bernard, E., and M. Fenton. 2007. Bats in a fragmented landscape: Species composition, diversity and habitat interactions in savannas of Santarém, Central Amazonia, Brazil. Biological Conservation 134:332-343.

Bianchi, F. J. J. A., C. J. H. Booij, and T. Tscharntke. 2006. Sustainable pest regulation in agricultural landscapes: a review on landscape composition, biodiversity and natural pest control. Proceedings of the Royal Society of Biological Sciences 273:1715-27.

Billeter, R., J. Liira, D. Bailey, R. Bugter, P. Arens, I. Augenstein, S. Aviron, J. Baudry, R. Bukacek, F. Burel, M. Cerny, G. De Blust, R. De Cock, T. Diekötter, H. Dietz, J. Dirksen, C. Dormann, W. Durka, M. Frenzel, R. Hamersky, F. Hendrickx, F. Herzog, S. Klotz, B. Koolstra, A. Lausch, D. Le Coeur, J. P. Maelfait, P. Opdam, M. Roubalova, A. Schermann, N. Schermann, T. Schmidt, O. Schweiger, M. J. M. Smulders, M. Speelmans, P. Simova, J. Verboom, W. K. R. E. Van Wingerden, M. Zobel, and P. J. Edwards. 2008. Indicators for biodiversity in agricultural landscapes: a pan-European study. Journal of Applied Ecology 45:141-150. 
Björklund, J., K. E. Limburg, and T. Rydberg. 1999. Impact of production intensity on the ability of the agricultural landscape to generate ecosystem services: An example from Sweden. Ecological Economics 29:269-291.

Boschi, C., and B. Baur. 2007. The effect of horse, cattle and sheep grazing on the diversity and abundance of land snails in nutrient-poor calcareous grasslands. Basic and Applied Ecology 8:55-65.

Boughey, K. L., I. R. Lake, K. A. Haysom, and P. M. Dolman. 2011. Improving the biodiversity benefits of hedgerows: How physical characteristics and the proximity of foraging habitat affect the use of linear features by bats. Biological Conservation 144:1790-1798.

Boutin, C., A. Baril, and P. A. Martin. 2008. Plant diversity in crop fields and woody hedgerows of organic and conventional farms in contrasting landscapes. Agriculture, Ecosystems and Environment 123:185-193.

Boyles, J. G., P. M. Cryan, G. F. Mccracken, and T. H. Kunz. 2011. Economic Importance of Bats in Agriculture. Science 332:41-42.

Boyles, J. G., C. L. Sole, P. M. Cryan, and G. F. McCracken. 2013. Chapter 24: On Estimating the Economic Value of Insectivorous Bats: Prospects and Priorities for Biologists. Pages 501-515 in R. A. Adams and S. C. Pedersen, editors. Bat Evolution, Ecology, and Conservation. Springer New York, New York, NY.

Brigham, R. M. 1991. Flexibility in Foraging and Roosting Behavior by the Big Brown Bat (Eptesicus fuscus). Canadian Journal of Zoology 69:117-121.

Broders, H. G., G. J. Forbes, S. Woodley, and I. D. Thompson. 2006. Range extent and stand selection for roosting and foraging in forest-dwelling Northern Long-eared Bats and Little Brown Bats in the Greater Fundy ecosystem, New Brunswick. Journal of Wildlife Management 70:1174-1184.

Burnham, K., and D. Anderson. 2003. Model Selection and Multimodel Inference: A Practical Information Theoretic Approach.

Burton, R. J. F., C. Kuczera, and G. Schwarz. 2008. Exploring Farmers' Cultural Resistance to Voluntary Agri-environmental Schemes. Sociologia Ruralis 48:16-37.

Campbell, L. A., J. G. Hallett, and M. A. O. Connell. 1996. Conservation of Bats in Managed Forests: Use of Roosts. Mammology 77:976-984.

Chamberlain, D. E., R. J. Fuller, R. G. H. Bunce, J. C. Duckworth, and M. Shrubb. 2000. Changes in the abundance of farmland birds in relation to the timing of agricultural intensification in England and Wales. Journal of Applied Ecology 37:771-788. 
Chester, E. T., and B. J. Robson. 2013. Anthropogenic refuges for freshwater biodiversity: Their ecological characteristics and management. Biological Conservation 166:64-75.

Clare, E. L., B. R. Barber, B. W. Sweeney, P. D. N. Hebert, and M. B. Fenton. 2011. Eating local: influences of habitat on the diet of little brown bats (Myotis lucifugus). Molecular Ecology 20:1772-80.

Clare, E. L., E. E. Fraser, H. E. Braid, M. B. Fenton, and P. D. N. Hebert. 2009. Species on the menu of a generalist predator, the eastern red bat (Lasiurus borealis): using a molecular approach to detect arthropod prey. Molecular Ecology 18:2532-42.

Colvin, R., G. R. Giannico, J. Li, K. L. Boyer, and W. J. Gerth. 2009. Fish Use of Intermittent Watercourses Draining Agricultural Lands in the Upper Willamette River Valley, Oregon. Transactions of the American Fisheries Society 138:13021313.

Davy, C. M., D. Russo, and M. B. Fenton. 2007. Use of native woodlands and traditional olive groves by foraging bats on a Mediterranean island: consequences for conservation. Journal of Zoology 273:397-405.

Devictor, V., and F. Jiguet. 2007. Community richness and stability in agricultural landscapes: The importance of surrounding habitats. Agriculture, Ecosystems and Environment 120:179-184.

Duchamp, J. E., D. W. Sparks, and J. O. Whitaker. 2004. Foraging-habitat selection by bats at an urban - rural interface : comparison between a successful and a less successful species. Forestry 1164:1157-1164.

Duchamp, J. E., and R. K. Swihart. 2008. Shifts in bat community structure related to evolved traits and features of human-altered landscapes. Landscape Ecology 23:849-860.

Dunning, J., B. Danielson, and H. Pulliam. 1992. Ecological processes that affect populations in complex landscapes. Oikos 65:169-175.

Elmore, L. W., D. A. Miller, and F. J. Vilella. 2005. Foraging Area Size and Habitat Use by Red Bats (Lasiurus borealis) in an Intensively Managed Pine Landscape in Mississippi. The American Midland Naturalist 153:405-417.

Erkert, H. G. 1982. Ecological aspects of bat activity rhythms. Pages 201-242 Kunz, T.H. (Ed.), Ecology of Bats. Plenum Press, New York, NY.

Estrada, A., and R. Coates-Estrada. 2002. Bats in continuous forest, forest fragments and in an agricultural mosaic habitat-island at Los Tuxtlas, Mexico. Biological Conservation 103:237-245. 
Ethier, K. 2010. M.Sc. Thesis: Positive effects of forest fragmentation, independent of forest amount, on bat abundance in eastern Ontario, Canada. Carleton.

Ethier, K., and L. Fahrig. 2011. Positive effects of forest fragmentation, independent of forest amount, on bat abundance in eastern Ontario, Canada. Landscape Ecology 26:865-876.

Fahrig, L., J. Baudry, L. Brotons, F. G. Burel, T. O. Crist, R. J. Fuller, C. Sirami, G. M. Siriwardena, and J.-L. Martin. 2011. Functional landscape heterogeneity and animal biodiversity in agricultural landscapes. Ecology Letters 14:101-112.

Fahrig, L., J. Girard, D. Duro, J. Pasher, A. Smith, S. Javorek, D. King, K. F. Lindsay, S. Mitchell, and L. Tischendorf. 2015. Farmlands with smaller crop fields have higher within-field biodiversity. Agriculture, Ecosystems \& Environment 200:219-234.

Fenton, M. 1992. Bats: Chapter 2 - Studying Bats. Facts on File, New York, NY.

Fenton, M., and G. Bell. 1981. Recognition of species of insectivorous bats by their echolocation calls. Journal of Mammalogy 62:233-243.

Fischer, J., J. Stott, B. S. Law, M. D. Adams, and R. I. Forrester. 2009. Designing Effective Habitat Studies: Quantifying Multiple Sources of Variability in Bat Activity. Acta Chiropterologica 11:127-137.

Foley, J. a, R. Defries, G. P. Asner, C. Barford, G. Bonan, S. R. Carpenter, F. S. Chapin, M. T. Coe, G. C. Daily, H. K. Gibbs, J. H. Helkowski, T. Holloway, E. a Howard, C. J. Kucharik, C. Monfreda, J. a Patz, I. C. Prentice, N. Ramankutty, and P. K. Snyder. 2005. Global consequences of land use. Science (New York, N.Y.) 309:570-4.

Frey-Ehrenbold, A., F. Bontadina, R. Arlettaz, and M. K. Obrist. 2013. Landscape connectivity, habitat structure and activity of bat guilds in farmland-dominated matrices. Journal of Applied Ecology 50:252-261.

Fuentes-Montemayor, E., D. Goulson, and K. J. Park. 2011. Pipistrelle bats and their prey do not benefit from four widely applied agri-environment management prescriptions. Biological Conservation 144:2233-2246.

Fuller, R. J., L. R. Norton, R. E. Feber, P. J. Johnson, D. E. Chamberlain, a C. Joys, F. Mathews, R. C. Stuart, M. C. Townsend, W. J. Manley, M. S. Wolfe, D. W. Macdonald, and L. G. Firbank. 2005. Benefits of organic farming to biodiversity vary among taxa. Biology Letters 1:431-4.

Garfinkel, M., and M. Johnson. 2015. Pest-removal services provided by birds on small organic farms in northern California. Agriculture, Ecosystems and Environment 211:24-31. 
Gehrt, S., and J. Chelsvig. 2004. Species-specific patterns of bat activity in an urban landscape. Ecological Applications 14:625-635.

Gorresen, P., and M. Willig. 2004. Landscape responses of bats to habitat fragmentation in Atlantic forest of Paraguay. Journal of Mammalogy 85:688-697.

Griffin, D., F. Webster, and C. Michael. 1960. The echolocation of flying insects by bats. Animal Behaviour 8:141-154.

Grueber, C. E., S. Nakagawa, R. J. Laws, and I. G. Jamieson. 2011. Multimodel inference in ecology and evolution: challenges and solutions. Journal of Evolutionary Biology 24:699-711.

Gruebler, M., M. Morand, and B. Naefdaenzer. 2008. A predictive model of the density of airborne insects in agricultural environments. Agriculture, Ecosystems and Environment 123:75-80.

Harvey, C. A., A. Medina, D. M. Sánchez, S. Vílchez, B. Hernández, J. C. Saenz, J. M. Maes, F. Casanoves, and F. L. Sinclair. 2006. Patterns of animal diversity in different forms of tree cover in agricultural landscapes. Ecological applications : a publication of the Ecological Society of America 16:1986-99.

Harvey, M., J. S. Altenbach, and T. Best. 2011. Bats of the United States and Canada. Johns Hopkins University Press.

Hecker, K. R., and R. M. Brigham. 1999. Does moonlight change vertical stratification of activity by forest-dwelling insectivorous bats? American Society of Mammalogists 80:1196-12011.

Hendrickx, F., J. P. Maelfait, W. Van Wingerden, O. Schweiger, M. Speelmans, S. Aviron, I. Augenstein, R. Billeter, D. Bailey, R. Bukacek, F. Burel, T. Diekötter, J. Dirksen, F. Herzog, J. Liira, M. Roubalova, V. Vandomme, and R. Bugter. 2007. How landscape structure, land-use intensity and habitat diversity affect components of total arthropod diversity in agricultural landscapes. Journal of Applied Ecology 44:340-351.

Holland, J., and L. Fahrig. 2000. Effect of woody borders on insect density and diversity in crop fields: A landscape-scale analysis. Agriculture, Ecosystems and Environment 78:115-122.

Humphrey, S. R. 1975. Nursery Roosts and Community Diversity of Nearctic Bats. Journal of Mammalogy 56:321-346.

Jantzen, M., and M. Fenton. 2013. The depth of edge influence among insectivorous bats at forest-field interfaces. Canadian Journal of Zoology 292:287-292. 
Jeswiet, S., L. Hermsen, and A. Division. 2015. Agriculture and wildlife : A two-way relationship. Statistics Canada EnviroStat:1-9.

Kalko, E. K. V., H.-U. Schnitzler, and E. K. V. Kalko. 2001. Echolocation by InsectEating Bats. BioScience 51:557.

Klug, P. E., L. L. Wolfenbarger, and J. P. McCarty. 2010. Snakes are Important Nest Predators of Dickcissels in an Agricultural Landscape. The Wilson Journal of Ornithology 122:799-803.

Krauel, J. J., J. K. Westbrook, and G. F. McCracken. 2014. Weather-driven dynamics in a dual-migrant system: moths and bats. Journal of Animal Ecology 84:608-614.

Kunz, T. H. 1988. Methods of Assessing the Availability of Prey to Insectivorous Bats. Pages 191-210 Ecological and Behavioral Methods for the Study of Bats. Smithsonian Institution Press, Washington, D.C.

Kunz, T. H., and S. Parsons. 2009. Ecological and Behaviour Methods for the Study of Bats. 2nd edition. The Johns Hopkins University Press, Baltimore, MD.

Kunz, T. H., E. B. de Torrez, D. Bauer, T. Lobova, and T. H. Fleming. 2011. Ecosystem services provided by bats. Annals of the New York Academy of Sciences 1223:138.

Lentini, P. E., P. Gibbons, J. Fischer, B. Law, J. Hanspach, and T. G. Martin. 2012. Bats in a farming landscape benefit from linear remnants and unimproved pastures. PloS one $7: \mathrm{e} 48201$.

Leslie, A. W., R. F. Smith, D. E. Ruppert, K. Bejleri, J. M. Mcgrath, B. A. Needelman, and W. O. Lamp. 2012. Environmental Factors Structuring Benthic Macro invertebrate Communities of Agricultural Ditches in Maryland. Environmental Entomology 41:802-812.

Limpens, H., W. Helmer, A. Van Winden, and K. Mostert. 1989. Bats (Chiroptera) and linear landscape elements. A review of our present knowledge of the importance of linear landscape elements to bats. Lutra 32:1-20.

Lovett, G. M., C. G. Jones, and M. G. Turner. 2004. Ecosystem Function in Heterogeneous Landscape. Springer Science, New York, NY.

Maine, J. J. 2014. M.Sc. Thesis: Trophic Ecology of Insectivorous Bats in Agroecosystems. Southern Illinois University Carbondale.

Marini, L., P. Fontana, S. Klimek, A. Battisti, and K. J. Gaston. 2009. Impact of farm size and topography on plant and insect diversity of managed grasslands in the Alps.

Biological Conservation 142:394-403. 
McCracken, G. F., J. K. Westbrook, V. A. Brown, M. Eldridge, P. Federico, and T. H. Kunz. 2012. Bats Track and Exploit Changes in Insect Pest Populations. Public Library of Science ONE 7:1-10.

Menzel, J. M., M. A. Menzel, J. C. Kilgo, W. M. Ford, T. C. Carter, and J. W. Edwards. 2003. Bats of the Savannah River Site and vicinity:1-69.

Michel, N., F. Burel, and A. Butet. 2006. How does landscape use influence small mammal diversity, abundance and biomass in hedgerow networks of farming landscapes? Acta Oecologica 30:11-20.

Nupp, T., and R. Swihart. 2000. Landscape-level correlates of small-mammal assemblages in forest fragments of farmland. Journal of Mammalogy 81:512-526.

O’Keefe, J. M., S. C. Loeb, J. D. Lanham, and H. S. Hill. 2009. Macrohabitat factors affect day roost selection by eastern red bats and eastern pipistrelles in the southern Appalachian Mountains, USA. Forest Ecology and Management 257:1757-1763.

Parsons, S., and G. Jones. 2000. Acoustic identification of twelve species of echolocating bat by discriminant function analysis and artificial neural networks. The Journal of Experimental Biology 203:2641-56.

Pasher, J., S. W. Mitchell, D. J. King, L. Fahrig, A. C. Smith, and K. E. Lindsay. 2013. Optimizing landscape selection for estimating relative effects of landscape variables on ecological responses. Landscape Ecology 28:371-383.

Patriquin, K. J., and R. M. R. Barclay. 2003. Foraging by bats in cleared, thinned and unharvested boreal forest. Journal of Applied Ecology 40:646-657.

Pocock, M. J. O., and N. Jennings. 2008. Testing biotic indicator taxa: the sensitivity of insectivorous mammals and their prey to the intensification. Journal of Applied Ecology 45:151-160.

Rotem, G., Y. Ziv, I. Giladi, and A. Bouskila. 2013. Wheat fields as an ecological trap for reptiles in a semiarid agroecosystem. Biological Conservation 167:349-353.

Russo, D., and G. Jones. 2002. Identification of twenty-two bat species (Mammalia: Chiroptera) from Italy by analysis of time-expanded recordings of echolocation calls. Journal of Zoology 258:91-103.

Rydell, J., A. Entwistle, and P. A. Racey. 2013. Timing of foraging flights of three species of bats in relation to insect activity predation risk activity. Oikos 76:243252. 
Smith, A. C., N. Koper, C. M. Francis, and L. Fahrig. 2009. Confronting collinearity: comparing methods for disentangling the effects of habitat loss and fragmentation. Landscape Ecology 24:1271-1285.

Sparks, D. W., C. M. Ritzi, and B. L. Everson. 2005. Nocturnal behavior and roosting ecology of a juvenile Lasiurus cinereus near Indianapolis, Indiana. Proceedings of the Indiana Academy of Science 114:70-72.

Statistics Canada. 2006. Census of Agriculture. http://www.statcan.gc.ca/cara2006/index-eng.htm.

Sunderland, K., and F. Samu. 2000. Effects of agricultural diversification on the abundance, distribution, and pest control potential of spiders: a review. Entomologia Experimentalis et Applicata:1-13.

Symondson, W. O. C., K. D. Sunderland, and M. H. Greenstone. 2002. Can Generalist Predators Be Effective Biocontrol Agents. Annual Review of Entomology 47:561594.

Thomas, D. W. 1988. The distrubtion of bats in different ages of Douglas-fir forests. The Journal of Wildlife Management 52:619-626.

Thompson, I. D. 2000. Forest vegetation of Ontario: factors influencing landscape change. Pages 30-53 A.H. Perera, D.L. Euler and I.D. Thompson, eds. Ecology of a Managed Terrestrial Landscape: Patterns and Processes of Forest Landscapes in Ontario. UBC Press.

Threlfall, C. G., B. Law, and P. B. Banks. 2012. Sensitivity of insectivorous bats to urbanization: Implications for suburban conservation planning. Biological Conservation 146:41-52.

Tonhasca, A., and D. N. Byrne. 1994. The effects of crop diversification on herbivorous insects: a meta-analysis approach. Ecological Entomology 19:239-244.

Trzcinski, M., L. Fahrig, and G. Merriam. 1999. Independent effects of forest cover and fragmentation on the distribution of forest breeding birds. Ecological Applications 9:586-593.

Tscharntke, T., A. M. Klein, A. Kruess, I. Steffan-Dewenter, and C. Thies. 2005. Landscape perspectives on agricultural intensification and biodiversity and ecosystem service management. Ecology Letters 8:857-874.

Vallan, D. 2000. Influence of forest fragmentation on amphibian diversity in the nature reserve of Ambohitantely, highland Madagascar. Biological Conservation 96:31-43. 
Verboom, B., and H. Huitema. 1997. The importance of linear landscape elements for the pipistrelle (Pipistrellus pipistrellus) and the serotine bat (Eptesicus serotinus). Landscape Ecologycology 12:117-125.

Walsh, A., R. Barclay, and G. McCracken. 2004. Designing bat activity surveys for inventory and monitoring studies at local and regional scales. Bat echolocation research: tools, techniques and analysis. Bat Conservation International, Austin, Texas.

Weilbull, A. C., and O. Ostman. 2003. Species composition in agroecosystems: The effect of lansdcape habitat, and farm management. Basic and Applied Ecology 4:349-361.

Whitaker, J. O. 1995. Food of the Big Brown Bat Eptesicus fuscus from Maternity Colonies in Indiana and Illinois Food of the Big Brown Bat Eptesicus fuscus from Maternity Colonies in Indiana and Illinois. American Midland Naturalist 134:346360 .

Wickramasinghe, L., and S. Harris. 2004. Abundance and species richness of nocturnal insects on organic and conventional farms: effects of agricultural intensification on bat foraging. Conservation Biology 18:1283-1292.

Wickramasinghe, L. P., S. Harris, G. Jones, and N. Vaughan. 2003. Bat activity and species richness on organic and conventional farms: impact of agricultural intensification. Journal of Applied Ecology 40:984-993.

Williams-Guillén, K., I. Perfecto, and J. Vandermeer. 2008. Bats Limit Insects System in a Neotropical Agroforestry. Science 320:70.

Van Zyll de Jong, C. G. 1985. Handbook of Canadian mammals, II, Bats. National Museums of Canada, Ottawa, Canada. 